\title{
The Interface between Extracellular and Transmembrane Domains of Homomeric Cys-Loop Receptors Governs Open- Channel Lifetime and Rate of Desensitization
}

\author{
Cecilia Bouzat, ${ }^{1}$ Mariana Bartos, ${ }^{1}$ Jeremías Corradi, ${ }^{1}$ and Steven M. Sine ${ }^{2}$ \\ ${ }^{1}$ Instituto de Investigaciones Bioquímicas, Universidad Nacional del Sur-Consejo Nacional de Investigaciones Científicas y Técnicas, Bahía Blanca 8000, \\ Argentina, and ${ }^{2}$ Receptor Biology Laboratory, Departments of Physiology and Biomedical Engineering and Neurology, Mayo Clinic College of Medicine, \\ Rochester, Minnesota 55905
}

\begin{abstract}
The lifetimes of activated postsynaptic receptor channels contribute to the efficiency of synaptic transmission. Here we show that structural differences within the interface dividing extracellular and transmembrane domains of homomeric $\alpha 7$ and 5-HT ${ }_{3 \mathrm{~A}}$ receptors account for the large differences in open-channel lifetime and time of desensitization onset between these contrasting members of the Cys-loop receptor superfamily. For $\alpha 7$ receptors, agonist-evoked single-channel currents appear mainly as isolated brief openings $\left(\tau_{\mathrm{o}}=\right.$ $0.35 \mathrm{~ms})$, whereas macroscopic currents after a step pulse of agonist desensitize rapidly $\left(\tau_{\mathrm{d}}=0.4 \mathrm{~ms}\right)$. In contrast for 5 -HT $3 \mathrm{~A}$ receptors, agonist-evoked single-channel currents appear as clusters of many long openings in quick succession $\left(\tau_{\text {cluster }}=1.2 \mathrm{~s}\right)$, whereas macroscopic currents desensitize slowly $\left(\tau_{\mathrm{d}}=1.1 \mathrm{~s}\right)$. A chimeric $\alpha 7-5 \mathrm{HT}_{3 \mathrm{~A}}$ receptor exhibits functional properties intermediate between those of the parent receptors, but the functional signatures of each parent are reconstituted after substituting the major loops within the interface of the extracellular and transmembrane domains from the corresponding parent receptor. Furthermore, these structural loops contribute to open-channel lifetime and time of desensitization onset in a nonadditive manner. The results suggest that desensitization is the major determinant of the lifetimes of activated $\alpha 7$ and $5-\mathrm{HT}_{3 \mathrm{~A}}$ receptors and that functional differences between the two receptors arise primarily through structural differences at the interface between extracellular and transmembrane domains.
\end{abstract}

Key words: nicotinic receptor; Cys-loop receptor; patch-clamp; desensitization; ion channel; chimera

\section{Introduction}

Whether a postsynaptic response triggers an action potential depends on the response amplitude and lifetime. If the amplitude is low, cable properties of the cell will attenuate the response below the action potential threshold, whereas if the lifetime is brief, the cell capacitance will reduce the response amplitude. Response amplitude depends on the number, probability of opening, and conductance of neurotransmitter-activated channels, whereas response lifetime depends on the stability of the open channel together with the probability the channel will reopen after a closing. At the motor synapse, nerve-released ACh rises and falls in a submillisecond pulse, and the response lifetime is dictated by the rates of channel closing (Magleby and Stevens, 1972), channel opening, and ACh dissociation (Colquhoun and Sakmann, 1981); desensitization does not contribute to open-channel life-

Received Jan. 31, 2008; revised May 2, 2008; accepted May 5, 2008.

This work was supported by National Institutes of Health Grant NS053521 (S.M.S., C.B.) and grants from Universidad Nacional del Sur, Agencia Nacional de Promoción Científica y Tecnológica, Loreal-Unesco, and Consejo Nacional de Investigaciones Científicas y Técnicas Argentina (C.B.). We thank Drs. Hai-Long Wang and Nuriya Mukhtasimova for contributions in the development of this work and Chris Free for technical contributions.

Correspondence should be addressed to either of the following: Dr. Cecilia Bouzat, Instituto de Investigaciones Bioquímicas, Universidad Nacional del Sur-Consejo Nacional de Investigaciones Científicas y Técnicas, Bahía Blanca 8000, Argentina, E-mail: inbouzat@criba.edu.ar; or Dr. Steven M. Sine, Mayo Clinic College of Medicine, Rochester, MN 55905, E-mail: sine@mayo.edu.

DOI:10.1523/JNEUROSCI.0448-08.2008

Copyright $\odot 2008$ Society for Neuroscience $\quad$ 0270-6474/08/287808-12\$15.00/0 time because it develops after tens of milliseconds to seconds of agonist exposure (Katz and Thesleff, 1957; Dilger and Liu, 1992). However, for AMPA receptors, the postsynaptic response and desensitization develop on similar timescales (Jones and Westbrook, 1996). Thus, among different classes of synaptic receptors, diverging mechanisms determine open-channel lifetime.

Receptors of the Cys-loop superfamily comprise a major class of ligand-coupled ion channels (Lester et al., 2004; Sine and Engel, 2006). They contain five subunits, each containing a signature sequence of 13 residues flanked by cysteine residues that form a loop at the junction of the binding and pore domains. Cys-loop receptors assemble from five copies of one subunit, forming homomeric receptors, or from several types of subunits, forming heteromeric receptors. The ancestral Cys-loop receptor was likely homomeric, suggesting that present day homomeric receptors are good models for probing structure-function relationships.

The agonist binding site of Cys-loop receptors projects into the synaptic cleft, whereas the region that gates ion flow localizes within the membrane (Unwin, 2005). Communication over the $50 \AA$ separating the two regions is thus central to the function of Cys-loop receptors. To date, three distinct parts of the receptor have been shown to relay agonist binding to the channel. They include a hairpin structure at the binding site called the C-loop (Mukhtasimova et al., 2005), residues spanning subunit inter- 


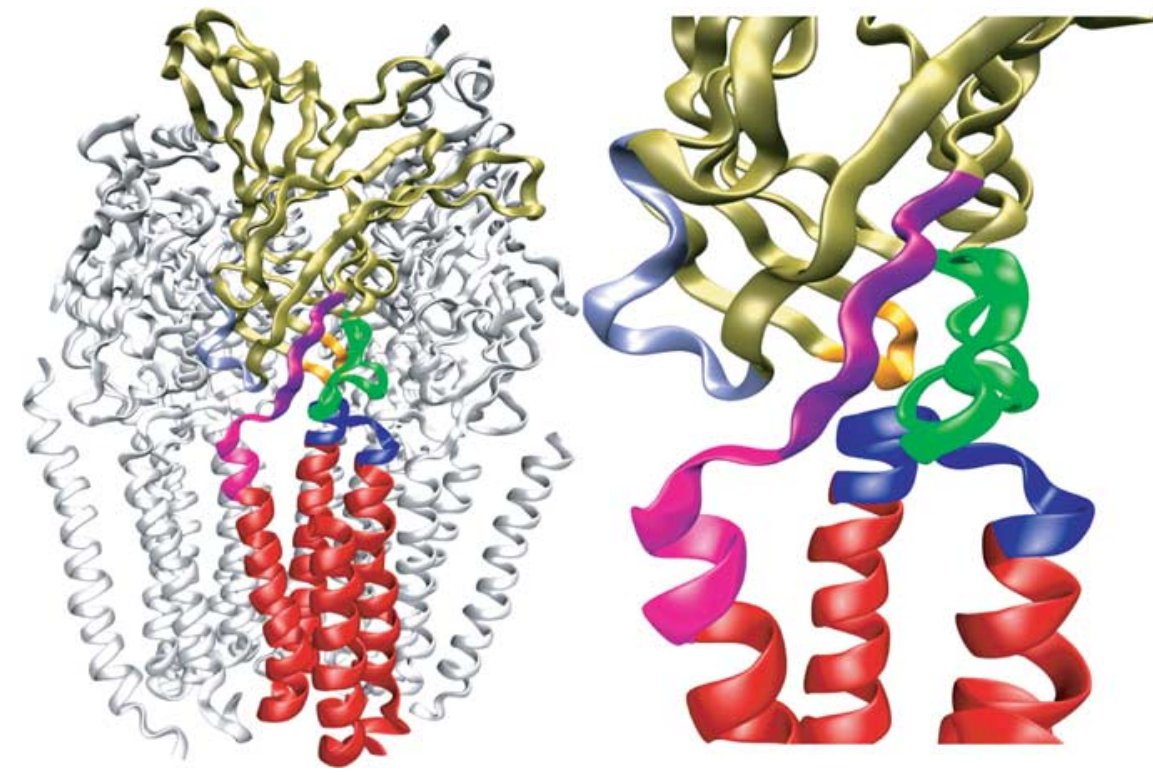

Figure 1. The interface dividing extracellular and transmembrane domains of the Torpedo AChR structural model at $4 \AA$ resolution (Protein Data Bank identification number 2BG9). $\boldsymbol{a}$, One of the $\alpha$ subunits of the pentamer is highlighted with the extracellular domain in yellow and transmembrane domain in red. $\boldsymbol{b}$, Close-up view of the interface from $\boldsymbol{a}$, with the Cys loop (green), M2-M3 loop (blue), $\beta 1-\beta 2$ loop (orange), $\beta 8-\beta 9$ loop (gray), C terminus of $\beta$-strand 10 (magenta), and $N$ terminus of M1 (pink). Images were generated with VMD software (Humphrey et al., 1996).

Table 1. Sequence comparisons between homomeric $\alpha 7$ and $5-\mathrm{HT}_{3 A}$ receptors

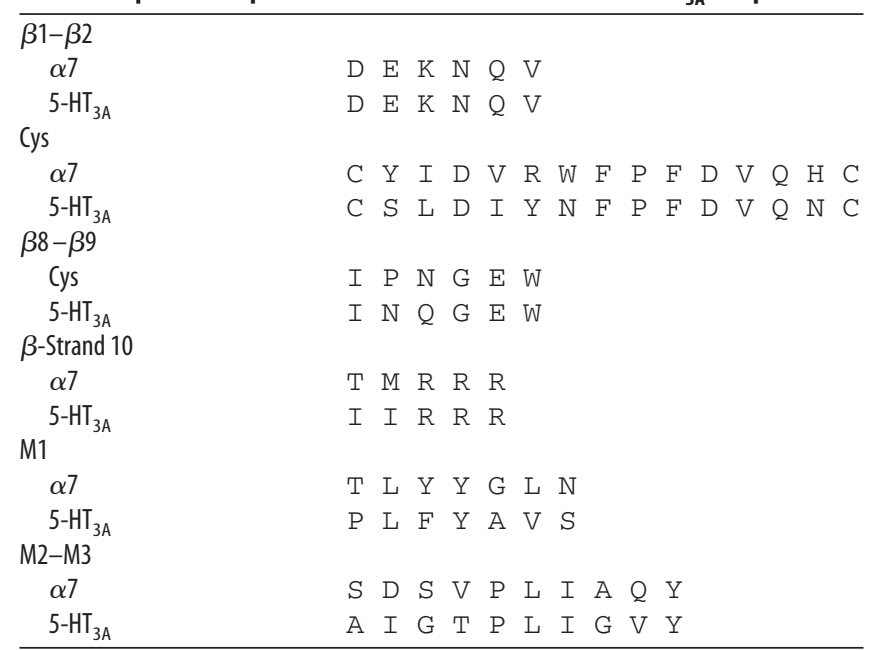

faces (Mukhtasimova and Sine, 2007), a network of loops at the junction of the extracellular and transmembrane domains (Kash et al., 2003; Bouzat et al., 2004; Chakrapani et al., 2004; Grutter et al., 2005; Lee and Sine, 2005; Lummis et al., 2005; Reeves et al., 2005; Xiu et al., 2005; Castillo et al., 2006; Mercado and Czajkowski, 2006; Gee et al., 2007; Jha et al., 2007). The interface dividing extracellular and transmembrane domains has attracted attention because it is a structural transition zone in which $\beta$-sheets from the binding domain merge with $\alpha$-helices from the pore (see Fig. 1). Within this zone, several loops form a network that relays structural changes from the binding site toward the pore.

To understand structural and mechanistic determinants of synaptic responses mediated by homomeric Cys-loop receptors, we measured single-channel and macroscopic currents through $\alpha 7$ and serotonin type $3 \mathrm{~A}\left(5-\mathrm{HT}_{3 \mathrm{~A}}\right)$ receptors. Although homol- ogous, these receptors diverge functionally, offering the opportunity to delineate structure-function relationships by generating chimeras. By substituting loops within the interface dividing extracellular and transmembrane domains of $\alpha 7$ and $5-\mathrm{HT}_{3 \mathrm{~A}}$ receptors, we find that the interface governs the lifetime of the open channel and rate of desensitization.

\section{Materials and Methods}

Site-directed mutagenesis and expression of receptors. Mutant and chimeric subunit cDNAs (Fig. 1, Table 1) were constructed using the QuikChange Site-Directed Mutagenesis kit (Stratagene) and were confirmed by sequencing the entire coding region. The $\alpha 7-5 \mathrm{HT}_{3 \mathrm{~A}}$ chimeric subunit used here differs by one residue from that described previously (Quiram and Sine, 1998; Rayes et al., 2005). The sequence at the chimeric junction is PYPDVTFTVIIR, in which the first nine residues are from human $\alpha 7$ and the last three are from mouse $5-\mathrm{HT}_{3 \mathrm{~A}}$. The difference is the underlined Val, which was Ile previously. The high-conductance forms of the mouse $5-\mathrm{HT}_{3 \mathrm{~A}}$ and $\alpha 7-5 \mathrm{HT}_{3 \mathrm{~A}}$ receptors were constructed as described previously (Bouzat et al., 2004; Rayes et al., 2005). Briefly, three arginine residues responsible for low conductance of receptors containing the $5-\mathrm{HT}_{3 \mathrm{~A}}$ pore region were mutated as follows: R432Q, R436D, and R440A (Kelley et al., 2003). BOSC 23 cells were transfected with the receptor subunit cDNAs using calcium phosphate precipitation, as described previously (Bouzat et al., 1994, 2000, 2002). To promote receptor expression on the cell surface, the human $\alpha 7 \mathrm{cDNA}$ was cotransfected with cDNA encoding Ric-3 (Williams et al., 2005), which was generously provided by Dr. William Green (University of Chicago, Chicago, IL). A plasmid encoding green fluorescent protein was included in all transfections to allow identification of transfected cells under fluorescence optics. Cells were used for single-channel and macroscopic current measurements 1 or $2 \mathrm{~d}$ after transfection.

Steady-state ACh binding. Transfected cells were harvested by gentle agitation in PBS, centrifuged at $1000 \times g$ for $1 \mathrm{~min}$, and resuspended in potassium Ringer's solution ( $140 \mathrm{~mm} \mathrm{KCl,} 5.4 \mathrm{~mm} \mathrm{NaCl}, 1.8 \mathrm{~mm} \mathrm{CaCl}_{2}$, $1.7 \mathrm{mM} \mathrm{MgCl}_{2}, 25 \mathrm{~mm}$ HEPES, and $30 \mathrm{mg} / \mathrm{L}$ bovine serum albumin, adjusted to $\mathrm{pH} 7.4$ with $10-11 \mathrm{~mm} \mathrm{NaOH}$ ). Agonist binding was determined by competition of specified concentrations of ACh against the initial rate of $\left[{ }^{125} \mathrm{I}\right] \alpha$-bungarotoxin $(\alpha$-BTX) binding as described previously (Sine et al., 1995a). The total number of binding sites was determined by incubating cells with $25 \mathrm{~nm}\left[{ }^{125} \mathrm{I}\right] \alpha$-BTX for $1 \mathrm{~h}$ and subtracting a blank determined in the presence of $1 \mathrm{~mm} d$-tubocurarine. After computing fractional occupancy from the initial rates of toxin binding (Sine and Taylor, 1979), the following equation was fitted to the data: 1 -fractional occupancy $=1-[L]^{n H} /\left([L]^{n H}+K_{d}{ }^{n H}\right)$, where $[L]$ is agonist concentration, $K_{d}$ is the apparent dissociation constant, and $n H$ is the Hill coefficient.

Patch-clamp recordings. Single-channel recordings were obtained in the cell-attached patch configuration (Hamill et al., 1981) at a membrane potential of $-70 \mathrm{mV}$ and at $20^{\circ} \mathrm{C}$, essentially as described previously (Bouzat et al., 2004; Rayes et al., 2005). For the receptor chimeras, all- $\alpha 7$ and $\mathrm{CH} 7$ single-channel currents could not be detected from cellattached patches; thus, unitary currents were recorded from outside-out patches. The bath and pipette solutions contained $140 \mathrm{~mm} \mathrm{KCl,} 5.4 \mathrm{~mm}$ $\mathrm{NaCl}, 0.2 \mathrm{~mm} \mathrm{CaCl}_{2}$, and $10 \mathrm{~mm}$ HEPES, pH 7.4. Patch pipettes were pulled from 7052 capillary tubes (Garner Glass) and coated with Sylgard (Dow Corning). Single-channel currents were recorded using an Axopatch $200 \mathrm{~B}$ patch-clamp amplifier (Molecular Devices), digitized at $5 \mu \mathrm{s}$ intervals with the PCI-6111E interface (National Instruments), and detected by the half-amplitude threshold criterion using the program TAC 

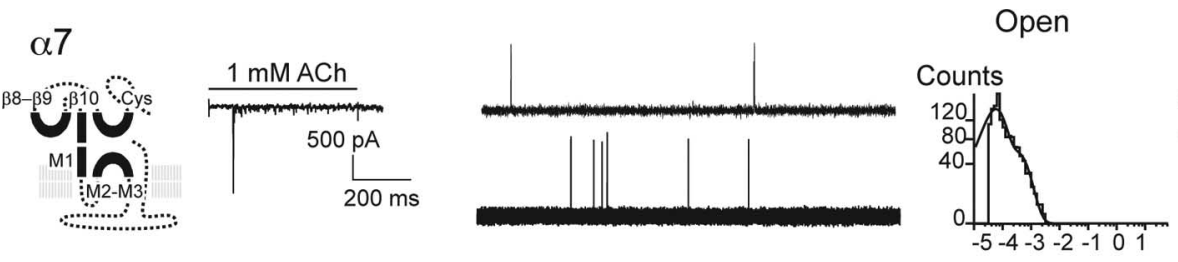

Closed
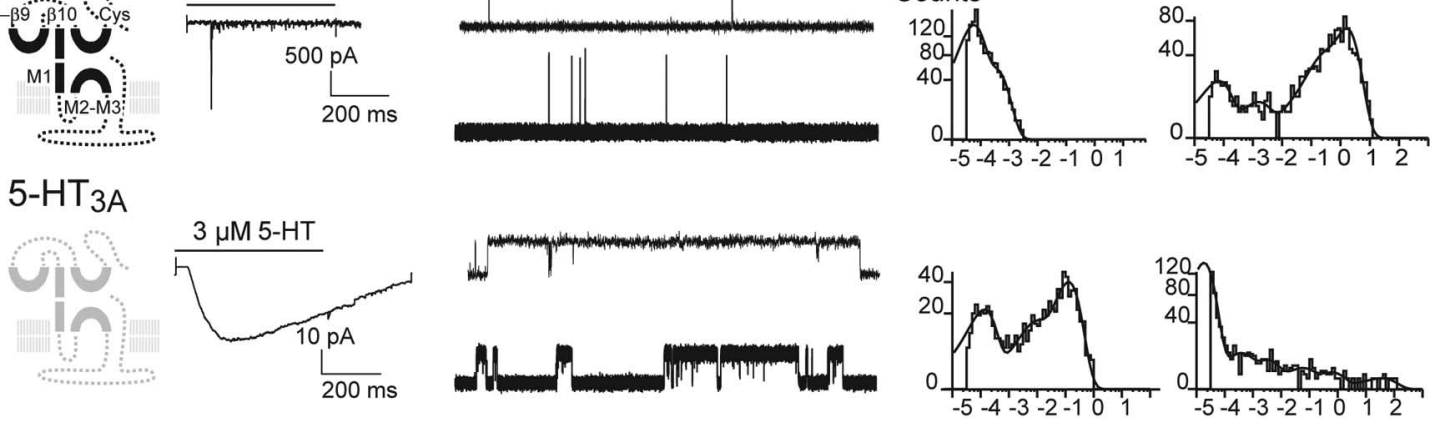

$\alpha 7-5 \mathrm{HT}_{3 \mathrm{~A}}$
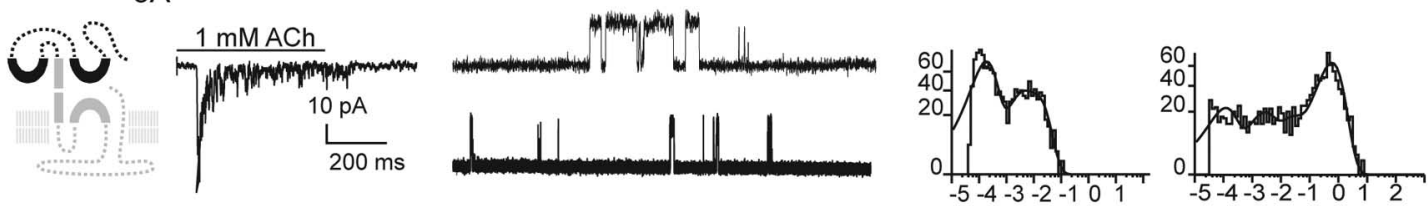

all-5 $5 \mathrm{HT}_{3 \mathrm{~A}}$
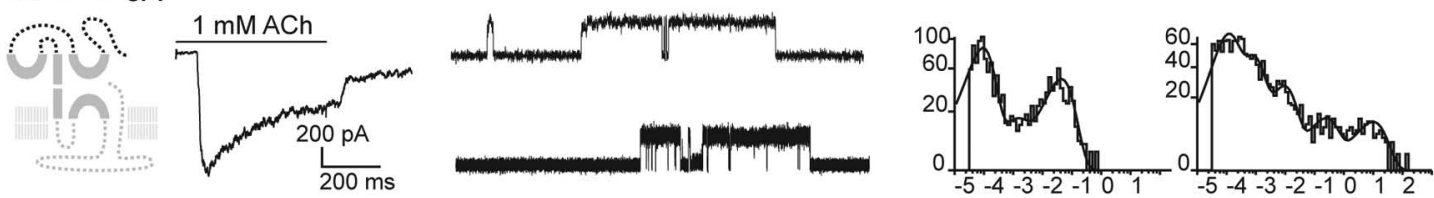

all- $\alpha 7$
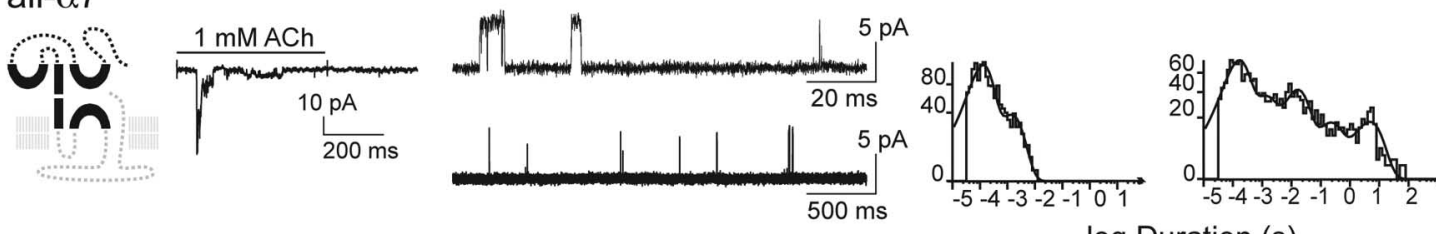

log Duration (s)

Figure 2. The interface dividing extracellular and transmembrane domains governs open-channel lifetime and rate of desensitization. Left column shows schematic diagrams of the receptors and interfaces, with each symbol representing a different segment of the linear sequence; $\alpha 7$ symbols are in black, and $5-\mathrm{HT}_{3 \mathrm{~A}}$ symbols are in gray. Middle column displays macroscopic currents recorded from outside-out patches rapidly perfused with a $500 \mathrm{~ms}$ pulse of $1 \mathrm{~mm} \mathrm{ACh} \mathrm{or} 3 \mu \mathrm{m} 5$-HT. Membrane potential, $-50 \mathrm{mV}$. Time constants for current decay are given in Table 2 . Right columns display single-channel currents and open and closed time histograms obtained from cells expressing the specified receptor. The dwell time distributions are fitted by sums of exponentials (smooth curves). For $\alpha 7,5-\mathrm{HT}_{3 \mathrm{~A}}, \alpha 7-5 \mathrm{HT}_{3 \mathrm{~A}}$, and all-5HT $3 \mathrm{~A}$, currents were recorded in the cell-attached patch configuration at $-70 \mathrm{mV}$ as described in Table 2 . For the all- $\alpha 7$ chimera, single-channel currents were recorded from outside-out patches rapidly perfused with $1 \mathrm{~mm} \mathrm{ACh}$ at $-70 \mathrm{mV}$. Openings are upward deflections. Mean durations of the longest open component are given in Table 2. For 5 - $\mathrm{HT}_{3 \mathrm{~A}}$ receptors and $\alpha 7-5 \mathrm{HT}_{3 \mathrm{~A}}$ chimeras, the high-conductance forms were used (see Materials and Methods).

4.0.10 (Bruxton Corporation) at a final bandwidth of $10 \mathrm{kHz}$ (Bouzat et al., 2000; Rayes et al., 2005). Dwell time histograms were plotted using a logarithmic abscissa and a square root ordinate (Sigworth and Sine, 1987) and fitted to the sum of exponential functions by maximum likelihood using the program TACFit (Bruxton Corporation). The duration of the longest component of openings, or apparent mean open time, was used to compare open-channel lifetimes among the chimeras. To estimate kinetic parameters for the $\alpha 7$ receptor, the apparent mean open time was corrected for missed events by dividing the total time corresponding to long-duration openings by the total number of closings associated with these openings.

Bursts were identified as a series of closely spaced openings preceded and followed by closed intervals longer than a specified critical duration $\left(t_{\text {crit }}\right)$. This duration was taken as the point of intersection of the first and second briefest components in the closed time histogram. Mean burst duration was determined from the longest component of the open time histogram constructed with an imposed $t_{\text {crit }}$. Thus, each series of opening events spaced by durations briefer than $t_{\text {crit }}$ was grouped to form a single burst. For receptors in which channel activity appeared in clear clusters, the critical time for defining clusters was set to the intersection of the second and third briefest components, which varied little among recordings. As described for bursts, mean cluster duration was obtained from open time histograms constructed with the corresponding $t_{\text {crit }}$.
For outside-out patch recordings, the pipette solution contained 134 mM KCl, 5 mm EGTA, $1 \mathrm{~mm} \mathrm{MgCl}_{2}$, and $10 \mathrm{~mm}$ HEPES, pH 7.3. For recordings from $5-\mathrm{HT}_{3 \mathrm{~A}}$ and chimeric receptors, extracellular solution (ECS) contained $150 \mathrm{~mm} \mathrm{NaCl}, 0.5 \mathrm{~mm} \mathrm{CaCl}_{2}$, and $10 \mathrm{~mm} \mathrm{HEPES,} \mathrm{pH}$ 7.3. For recordings from $\alpha 7$ receptors, ECS contained $150 \mathrm{~mm} \mathrm{NaCl}, 1.8$ $\mathrm{mm} \mathrm{CaCl}_{2}, 1 \mathrm{~mm} \mathrm{MgCl}_{2}$, and $10 \mathrm{~mm}$ HEPES, $\mathrm{pH}$ 7.3. A series of applications of ECS containing agonist was applied to the patch as described previously (Liu and Dilger, 1991; Spitzmaul et al., 2001). Briefly, the perfusion system consisted of solution reservoirs suspended on a pole for gravity-driven flow, switching valves, a solenoid-driven pinch valve, and two tubes (inner diameter of $0.3 \mathrm{~mm}$ ) oriented at $90^{\circ}$ into the culture dish. One tube contained ECS without agonist and the other contained ECS with agonist. The pipette with the outside-out patch was located within several hundred micrometers of the two output tubes in which streams coming from both tubes would intersect. When the pinch valve was switched, solution flowed from only one side at a time and switched from one side to the other. This perfusion system allowed for a rapid exchange of the solution bathing the patch. The solution exchange time was estimated by stepping the patch held at $0 \mathrm{mV}$ in bath solution and then applying a $500 \mathrm{~ms}$ pulse of bath solution diluted 1:2 with water. Typical exchange times ranged from 0.1 to $1 \mathrm{~ms}$.

Macroscopic currents were recorded at a holding potential of -50 $\mathrm{mV}$, filtered at $5 \mathrm{kHz}$, and digitized at $20 \mathrm{kHz}$. Data analysis was per- 

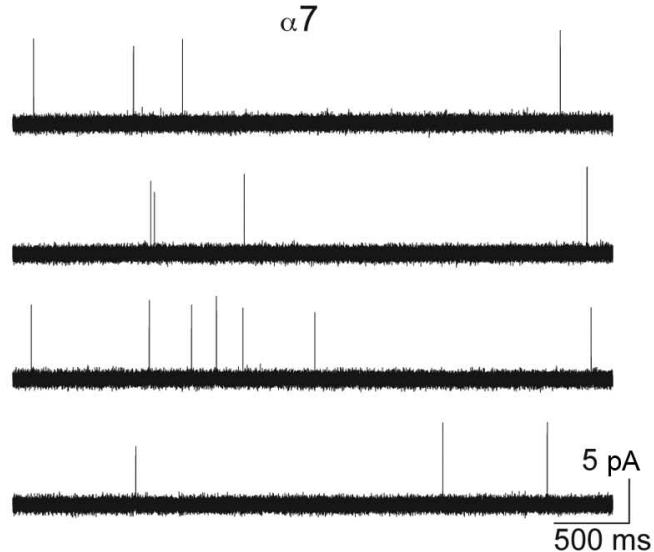

$5-\mathrm{HT}_{3 \mathrm{~A}}$
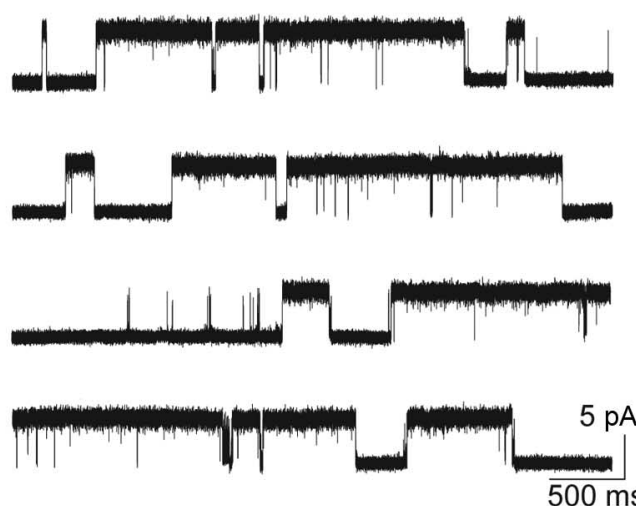

b

Closed

Counts

Open

Burst

$\alpha 7$
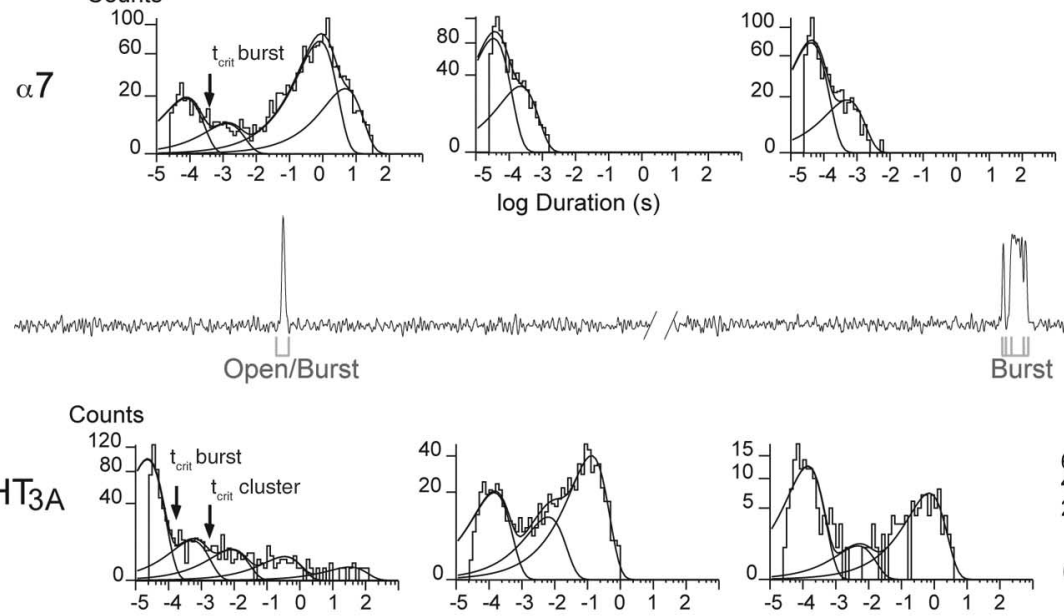

log Duration (s)

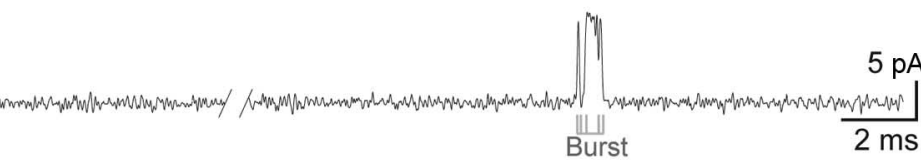

Cluster
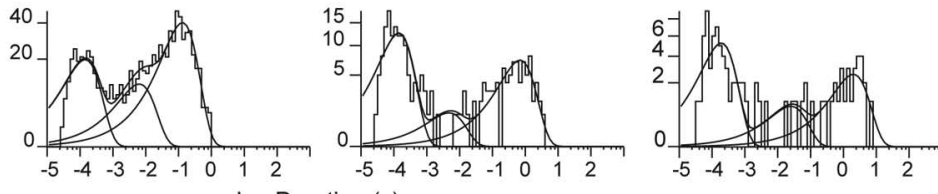

log Duration (s)

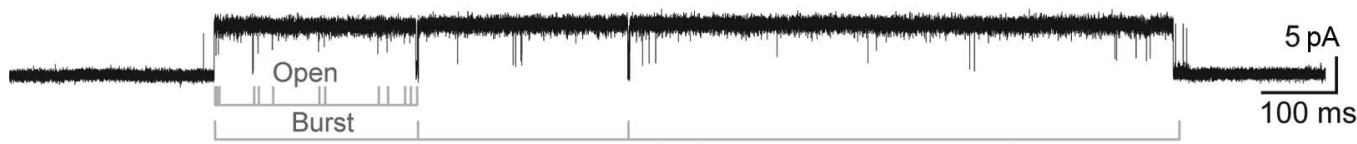

Cluster

Figure 3. Single-channel currents of $\alpha 7$ and 5- $\mathrm{HT}_{3 \mathrm{~A}}$ receptors. Recordings were made in the cell-attached patch configuration at an applied potential of $-70 \mathrm{mV}$. $\alpha 7$ receptors were activated by $100 \mu \mathrm{m}$ ACh, and the high-conductance form of $5-\mathrm{HT}_{3 \mathrm{~A}}$ receptors was activated by $3 \mu \mathrm{m} 5-\mathrm{HT}$. $\boldsymbol{a}$, Channel traces corresponding to each receptor. Notice isolated openings for $\alpha 7$ and long clusters of openings for $5-\mathrm{HT}_{3 \mathrm{~A}}$ receptors. Filter, $9 \mathrm{kHz}$. $\boldsymbol{b}$, Representative dwell time histograms for both receptors are shown. For $\alpha 7$ receptors, the briefest closed component is systematically observed in all recordings. The average mean duration and relative area of this component is $117 \pm 35 \mu \mathrm{s}(0.15 \pm 0.03 ; n=4)$. The other closed time components were variable and depended on the expression level. The critical time for defining bursts $\left(t_{\text {crit }}\right)$ was taken as the point of intersection of the first and second closed time components. For most recordings, $t_{\text {crit }}$ ranged from 0.4 and $1 \mathrm{~ms}$. The fitted mean dwell times and relative areas of components in the open time histogram are $28 \mu \mathrm{s}(0.74)$ and $215 \mu \mathrm{s}(0.26)$. The burst duration histogram constructed with $t_{\text {crit }}=0.5 \mathrm{~ms}$ is fitted by two components [37 $\mu \mathrm{s}(0.79)$ and $400 \mu \mathrm{s}(0.21)$ ]. The longest component corresponds to bursts. Clusters are not observed for $\alpha 7$ receptors at any $\mathrm{ACh}_{\text {Concentration }}$. For 5 - $\mathrm{HT}_{3 \mathrm{~A}}$ receptors, closed time histograms are fitted by five to six components. The average mean duration and relative area of the briefest component, which corresponds to closings within bursts, is $29 \pm 10 \mu \mathrm{s}(0.80 \pm$ $0.07 ; n=3)$. However, some recordings are better fitted by two brief intraburst components. The succeeding brief closed time component $(1.0 \pm 0.6 \mathrm{~ms}$, relative to $0.11 \pm 0.02 ; n=3)$ is also constant among recordings and corresponds to closings within clusters. For the majority of recordings, $t_{\text {crit }}$ was $0.15-0.50 \mathrm{~ms}$ for defining bursts and $4-10 \mathrm{~ms}$ for defining clusters. In the example, the durations of open time components are $150 \mu \mathrm{s}(0.29), 6 \mathrm{~ms}(0.14)$, and $130 \mathrm{~ms}(0.57)$. The burst duration histogram constructed with $t_{\text {crit }}=0.15 \mathrm{~ms}$ is fitted by three components [ $150 \mu \mathrm{s}(0.61)$, $7 \mathrm{~ms}(0.05)$, and $685 \mathrm{~ms}(0.34)]$. The longest-duration component corresponds to bursts. The longest component of the cluster duration histogram constructed with $t_{\text {crit }}=4 \mathrm{~ms}$ is $1.9 \mathrm{~s}($ relative area $0.27)$.

formed using the IgorPro software (WaveMetrics). Currents from $\alpha 7$ $5 \mathrm{HT}_{3 \mathrm{~A}}$ chimeras were elicited by $1 \mathrm{~mm} \mathrm{ACh}$; at this concentration, openchannel block by ACh is negligible, given the dissociation constant for block of $40 \mathrm{~mm}$ for the $\alpha 7-5 \mathrm{HT}_{3 \mathrm{~A}}$ chimera (Rayes et al., 2005).

For recordings from $\alpha 7$ receptors, the ensemble mean current was calculated for 5-10 individual current traces. Current records were aligned at the point at which the current reached $50 \%$ of maximum. Because currents through $\alpha 7$ receptors decayed rapidly, the mean decay time constant was the average of 28 individual currents recorded from six different outside-out patches. Current decays were fitted by the following function: $I_{(t)}=I_{0} \exp \left(-t / \tau_{\mathrm{d}}\right)+I_{\infty}$, where $I_{0}$ and $I_{\infty}$ are the peak and the steady-state current values, respectively, and $\tau_{\mathrm{d}}$ is the decay time constant. In the presence of a high concentration of agonist, if the probability of channel opening is high and the recovery rate from desensitization in the presence of agonist is relatively slow (estimated from the size of the steady state current), the value of $1 / \tau_{\mathrm{d}}$ approaches the rate constant for entering the desensitized state.

Single-channel and macroscopic currents through $5-\mathrm{HT}_{3 \mathrm{~A}}$ receptors 
were elicited by $3 \mu \mathrm{m} 5$-HT. This concentration is greater than the $\mathrm{EC}_{50}$ determined from the relationship between the peak current and agonist concentration $\left(\mathrm{EC}_{50}=2.7 \pm 0.5 \mu \mathrm{M}\right.$ ) (Mott et al., 2001; Gumilar and Bouzat, 2008). Current decays were fitted by a single-exponential component, whereas at higher 5-HT concentrations two exponential components were required (Mott et al., 2001) (supplemental Fig. 1, available at www.jneurosci.org as supplemental material). The 5-HT concentration of $3 \mu \mathrm{M}$ was also chosen because higher concentrations decreased the mean open time (supplemental Fig. 1, available at www.jneurosci.org as supplemental material), in a manner consistent with open-channel block.

Macroscopic currents were simulated using QuB software (QUB Suite, State University of New York, Buffalo, NY) on the basis of Scheme 1 (see Results). For the simulations, we varied the channel opening rate, $\beta$, from 5000 to $20,000 \mathrm{~s}^{-1}$. The simulated currents were analyzed with SigmaPlot 7.101.

For $\alpha 7$ receptors, recovery from desensitization was determined by recording whole-cell currents at an applied potential of $-50 \mathrm{mV}$, and a $150 \mathrm{~ms}$ step pulse of $1 \mathrm{~mm}$ ACh was applied to the cells. After removal of $\mathrm{ACh}$, a second pulse of $1 \mathrm{~mm} \mathrm{ACh}$ was applied at intervals between 0.25 and $6 \mathrm{~s}$ after the end of the first ACh pulse. The fractional recovery of the current elicited by the second pulse was plotted against the interpulse interval.

\section{Results}

\section{Diverging functional properties of homomeric $\alpha 7$ and $5-\mathrm{HT}_{3 \mathrm{~A}}$ receptors}

We transfected BOSC 23 cells with cDNAs encoding homomeric $\alpha 7$ or $5-\mathrm{HT}_{3 \mathrm{~A}}$ receptors, formed cell-free outside-out patches, and recorded macroscopic currents elicited by a $500 \mathrm{~ms}$ step pulse of agonist (Fig. 2). High concentrations of agonist were chosen to simplify subsequent mechanistic analyses, but, to avoid channel block by the agonists, concentrations greater than the $\mathrm{EC}_{50}$ for activation but below the threshold for blocking were used (Rayes et al., 2005) (supplemental Fig. 1, available at www.jneurosci.org as supplemental material). Macroscopic current through $\alpha 7$ receptors decays rapidly from its peak $\left(\tau_{\mathrm{d}} \sim 0.4 \mathrm{~ms}\right)$, whereas current through $5-\mathrm{HT}_{3 \mathrm{~A}}$ receptors decays slowly $\left(\tau_{\mathrm{d}} \sim 1 \mathrm{~s}\right)$. In the presence of high agonist concentration and if the probability of channel opening is high and the rate of recovery from desensitization in the presence of agonist is slow, the value of $1 / \tau_{\mathrm{d}}$ approaches the desensitization rate. Because $5-\mathrm{HT}_{3 \mathrm{~A}}$ receptor channels are blocked by concentrations of 5-HT greater than the $\mathrm{EC}_{50}$, a saturating concentration of $5-\mathrm{HT}_{3 \mathrm{~A}}$ could not be used; thus, the rate of desensitization measured at the $\mathrm{EC}_{50}$ represents a lower bound. However, experiments in the presence of a saturating concentration of 5-HT show two exponential components, the slowest of which is only twofold faster than that in the presence of $3 \mu \mathrm{M}$ 5-HT (supplemental Fig. 1, available at www.jneurosci.org as supplemental material). Thus, $\alpha 7$ desensitize rapidly, whereas $5-\mathrm{HT}_{3 \mathrm{~A}}$ receptors desensitize slowly.

To determine the microscopic origin of the diverging kinetics of the two types of receptors, we recorded single-channel currents evoked by the same high concentrations of agonist. For $\alpha 7$ receptors, channel openings appear as single brief pulses flanked by long closed periods or less often as several pulses in quick succession (Figs. 2, 3). In contrast for $5-\mathrm{HT}_{3 \mathrm{~A}}$ receptors, openings are long and appear as many openings in quick succession (Figs. 2, 3). Thus, $\alpha 7$ receptors activate in episodes of one or a few brief openings and desensitize rapidly, whereas $5-\mathrm{HT}_{3 \mathrm{~A}}$ receptors activate in episodes of many long openings and desensitize slowly. The diverging kinetic profiles of the two types of receptors suggest that, at a synapse in which the pulse of neurotransmitter is transient, responses of $\alpha 7$ receptors are brief whereas responses of $5-\mathrm{HT}_{3 \mathrm{~A}}$ receptors are prolonged, whereas for both receptors

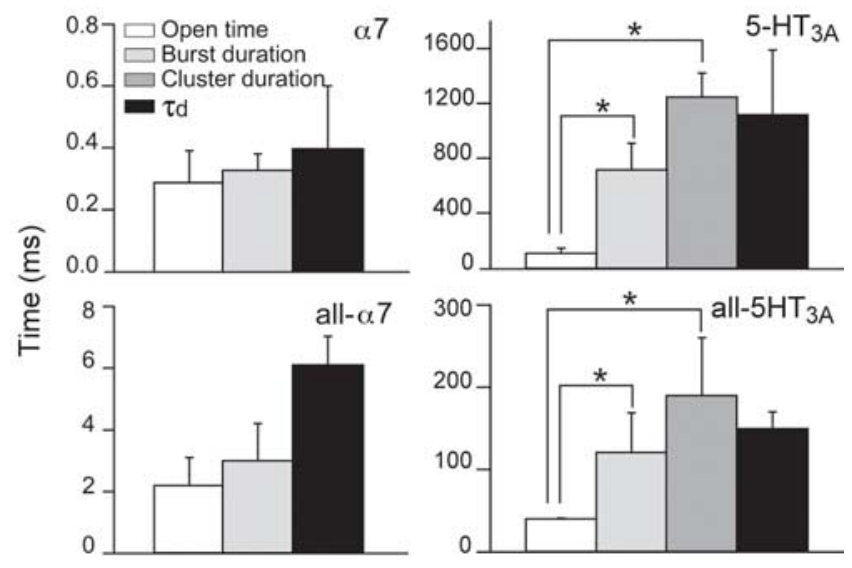

Figure 4. Comparison of open, burst, and cluster durations, and current decay time constant. Open, burst, and cluster duration histograms were obtained from single-channel recordings at $-70 \mathrm{mV}$ as described in Figure 2. The open time corresponds to the longest component of the open time histogram. Burst and cluster durations were determined by the longest component of the respective histograms constructed as described in Materials and Methods and Figure 3. Typical critical times for burst and cluster resolution were as follows: $5-\mathrm{HT}_{3 \mathrm{~A}}, 0.15-$ $0.50 \mathrm{~ms}$ (burst) and 4-10 ms (cluster); $\alpha 7,0.4-1 \mathrm{~ms}$ (burst); all- $5 \mathrm{HT}_{3 \mathrm{~A}}, 0.2-0.6 \mathrm{~ms}$ (burst) and $2-5 \mathrm{~ms}$ (cluster); all- $\alpha 7,0.4-1 \mathrm{~ms}$ (burst). $\tau_{\mathrm{d}}$ corresponds to the decay time constant of macroscopic currents elicited by $3 \mu \mathrm{M} 5-\mathrm{HT}\left(5-\mathrm{HT}_{3 \mathrm{~A}}\right)$ and $1 \mathrm{~mm} \mathrm{ACh}$ for $\alpha 7$, all-5HT $3 \mathrm{~A}$, and all- $\alpha 7$. Values are shown as mean \pm SD. Statistical significance was determined by Student's test. ${ }^{*} p<0.05$.

the lifetimes of the elementary responses are determined mainly by desensitization.

Single-channel dwell time histograms further distinguish the two types of receptors (Fig. 3). For $\alpha 7$ receptors, the distribution of open dwell times is described by the sum of two exponential components; openings within the brief component occur in isolation, whereas those within the long component occur both in isolation and within episodes of closely spaced openings called bursts. The distribution of closed dwell times is described by the sum of three or four exponential components; the briefest component corresponds to closings within bursts, whereas the longer components correspond to closings between independent openings, bursts, or both. To recognize bursts and quantify their durations, a critical closed time is defined as the point of intersection between the briefest and succeeding components, and openings separated by closings briefer than this time constitute a burst. Comparison of burst and open duration histograms reveals that, on forming bursts, the mean duration of the brief component is unchanged, but that of the long component increases (Fig. 3). Events within the slowest component of bursts whose mean durations overlap with those of openings likely consist of single opening episodes but are nevertheless considered bursts.

For $5-\mathrm{HT}_{3 \mathrm{~A}}$ receptors, the distribution of open dwell times is described by the sum of three exponential components (Fig. 3). Openings within the long component again appear as bursts of closely spaced openings, but bursts coalesce into higher-order pulse sequences called clusters; openings within the two brief components occur both within clusters and in isolation. The distribution of closed dwell times is described by the sum of five exponential components; the brief component dominates the distribution and corresponds to closings within intracluster bursts, the succeeding component corresponds to closings between intracluster bursts, whereas the remaining long components correspond to closings between independent clusters, isolated openings, or both. To define clusters, a critical closed time is defined as the point of intersection of the second briefest and the 
Table 2. Functional properties of homomeric $\alpha 7$ and 5- $-\mathrm{HT}_{3 \mathrm{~A}}$ receptors and chimeras

\begin{tabular}{|c|c|c|c|c|c|c|c|c|}
\hline Receptor & Cys loop & $\beta 8-\beta 9$ & $\beta$-strand 10 term & M1 term & $\mathrm{M} 2-\mathrm{M} 3$ & $K_{d}(\mu \mathrm{m})$ & $\tau_{0}(\mathrm{~ms})$ & $\tau_{\mathrm{d}}(\mathrm{ms})$ \\
\hline$\alpha 7$ & $\alpha 7$ & $\alpha 7$ & $\alpha 7$ & $\alpha 7$ & $\alpha 7$ & $9.2 \pm 0.80$ & $0.30 \pm 0.10$ & $0.40 \pm 0.20$ \\
\hline $5-\mathrm{HT}_{3 \mathrm{~A}}$ & $5-\mathrm{HT}_{3}$ & $5-\mathrm{HT}_{3}$ & $5-\mathrm{HT}_{3}$ & $5-\mathrm{HT}_{3}$ & $5-\mathrm{HT}_{3}$ & & $110 \pm 35$ & $1100 \pm 400$ \\
\hline$\alpha 7-5 \mathrm{HT}_{3 \mathrm{~A}}$ & $\alpha 7$ & $\alpha 7$ & $5-\mathrm{HT}_{3}$ & $5-\mathrm{HT}_{3}$ & $5-\mathrm{HT}_{3}$ & $56 \pm 4.2$ & $6.2 \pm 0.2$ & $10 \pm 2$ \\
\hline all- $5 \mathrm{HT}_{3 \mathrm{~A}}$ & $5-\mathrm{HT}_{3}$ & $5-\mathrm{HT}_{3}$ & $5-\mathrm{HT}_{3}$ & $5-\mathrm{HT}_{3}$ & $5-\mathrm{HT}_{3}$ & $1.2 \pm 0.18$ & $40 \pm 1$ & $150 \pm 20$ \\
\hline all- $\alpha 7$ & $\alpha 7$ & $\alpha 7$ & $\alpha 7$ & $\alpha 7$ & $\alpha 7$ & $1.4 \pm 0.40$ & $2.2 \pm 0.9$ & $5.9 \pm 2.3$ \\
\hline $\mathrm{CH} 1$ & $5-\mathrm{HT}_{3}$ & $\alpha 7$ & $5-\mathrm{HT}_{3}$ & $5-\mathrm{HT}_{3}$ & $5-\mathrm{HT}_{3}$ & $8.1 \pm 0.70$ & $37 \pm 3$ & $120 \pm 35$ \\
\hline $\mathrm{CH} 2$ & $\alpha 7$ & $5-\mathrm{HT}_{3}$ & $5-\mathrm{HT}_{3}$ & $5-\mathrm{HT}_{3}$ & $5-\mathrm{HT}_{3}$ & $2.6 \pm 0.09$ & $41 \pm 4$ & $280 \pm 90$ \\
\hline $\mathrm{CH} 3$ & $\alpha 7$ & $\alpha 7$ & $5-\mathrm{HT}_{3}$ & $\alpha 7$ & $5-\mathrm{HT}_{3}$ & $80 \pm 8.7$ & & \\
\hline $\mathrm{CH} 4$ & $\alpha 7$ & $\alpha 7$ & $\alpha 7$ & $\alpha 7$ & $5-\mathrm{HT}_{3}$ & $62 \pm 5.0$ & & \\
\hline $\mathrm{CH} 5$ & $\alpha 7$ & $\alpha 7$ & $\alpha 7$ & $5-\mathrm{HT}_{3}$ & $\alpha 7$ & $3.3 \pm 0.70$ & $62 \pm 4$ & $320 \pm 60$ \\
\hline $\mathrm{CH} 6$ & $\alpha 7$ & $\alpha 7$ & $5-\mathrm{HT}_{3}$ & $5-\mathrm{HT}_{3}$ & $\alpha 7$ & $2.4 \pm 0.60$ & $50 \pm 2$ & $310 \pm 80$ \\
\hline $\mathrm{CH} 7$ & $\alpha 7$ & $\alpha 7$ & $5-\mathrm{HT}_{3}$ & $\alpha 7$ & $\alpha 7$ & $0.80 \pm 0.15$ & $1.6 \pm 0.6$ & $3.4 \pm 1.5$ \\
\hline
\end{tabular}

$K_{d}$ is the apparent dissociation constant obtained from competition of ACh against $\alpha$-BTX binding. $\tau_{0}$ is the longest exponential component in the open time histogram obtained at a saturating concentration of agonist. $\tau_{d}$ is the time constant of current decay following rapid application of $1 \mathrm{~mm} \mathrm{ACh} \mathrm{to} \mathrm{outside-out} \mathrm{patches,} \mathrm{except} \mathrm{for} \mathrm{CH}_{2}$ for which the whole-cell configuration was used. For all experiments, the high-conductance form of 5 - $\mathrm{HT}$ 3A receptors was used (see Materials and Methods), and macroscopic currents were activated by $3 \mu \mathrm{m} 5$-HT. The $\tau_{\mathrm{d}}$ for $\alpha 7$ corresponds to the mean and SD of 28 responses to $1 \mathrm{~mm}$ ACh from a total of six outside-out patches. Agonist concentrations used to elicit

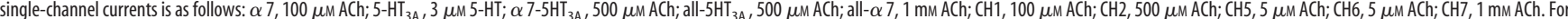
chimeras $\mathrm{CH} 5$ and $\mathrm{CH} 6$, very high concentrations of $\mathrm{ACh}$ could not be used because they elicited high channel activity with many superimposed events, which prevented quantitative analysis. Data indicate the mean and $\mathrm{SD}$ for three to nine different recordings for each condition.

succeeding components, and openings separated by closings shorter than this time constitute a cluster. Comparison of cluster and open duration histograms reveals that, on forming clusters, the mean duration of the brief and intermediate components are unchanged, but the mean duration of the long component increases (Fig. 3). For 5- $\mathrm{HT}_{3 \mathrm{~A}}$ receptors, openings appear in clusters even at the lowest 5-HT concentration that elicits detectable single-channel openings (supplemental Fig. 1, available at www. jneurosci.org as supplemental material), whereas for $\alpha 7$ receptors, openings do not appear in clusters at any ACh concentration (Fig. 3).

To quantify the kinetic signatures of $\alpha 7$ and 5- $\mathrm{HT}_{3 \mathrm{~A}}$ receptors, we computed the mean durations of openings, bursts, and clusters, and the time constant for desensitization (Fig. 4). For $\alpha 7$ receptors, the mean duration of long openings, the mean duration of bursts, and the time constant for desensitization are all similar. The mean burst duration of $0.33 \mathrm{~ms}$ is very close to the measured time constant for desensitization onset of $0.4 \mathrm{~ms}$; because most bursts consist of a single opening, desensitization is the predominant pathway for terminating a channel opening episode. In contrast for $5-\mathrm{HT}_{3 \mathrm{~A}}$ receptors, the mean duration of long openings is much briefer than either the mean cluster duration or the time constant for desensitization. The mean cluster duration is, however, similar to the time constant for desensitization, indicating that, for $5-\mathrm{HT}_{3 \mathrm{~A}}$ receptors, clusters are the single-channel counterpart of macroscopic desensitization. For the muscle $\mathrm{ACh}$ receptor (AChR) in which the probability of channel opening within a cluster is close to 1 , as observed here for clusters elicited by $5-\mathrm{HT}_{3 \mathrm{~A}}$ receptors, cluster duration depends on the rate of desensitization from the open state (Auerbach and Akk, 1998).

\section{Structural bases for the diverging functional properties of $\alpha 7$ and $5-\mathrm{HT}_{3 \mathrm{~A}}$ receptors}

To identify structural underpinnings of the diverging openchannel lifetimes and rates of desensitization for $\alpha 7$ and 5- $\mathrm{HT}_{3 \mathrm{~A}}$ receptors, we generated a chimeric receptor in which the ligand binding domain contained $\alpha 7$ sequence and the pore and cytoplasmic domains contained 5- $\mathrm{HT}_{3 \mathrm{~A}}$ sequence (Rayes et al., 2005). After transfecting the cDNA encoding the $\alpha 7-5 \mathrm{HT}_{3 \mathrm{~A}}$ chimera into BOSC 23 cells, we formed outside-out patches, applied a 500 ms pulse of a saturating concentration of $\mathrm{ACh}$, and recorded macroscopic currents. After a rapid rise, the currents decay at a rate intermediate between that for the two parent receptors (Fig. 2 , Table 2 ). In cell-attached patch recordings at a high concentration of ACh, single-channel openings from the $\alpha 7-5 \mathrm{HT}_{3 \mathrm{~A}}$ chimera appear as isolated brief openings, bursts of several long openings, or bursts of brief and long openings (Fig. 2). Open time histograms are described by the sum of three exponential components, the longest of which is intermediate between the long components from the two parent receptors (Fig. 2, Table 2) (Rayes et al., 2005). Thus, for the $\alpha 7-5 \mathrm{HT}_{3 \mathrm{~A}}$ chimeric receptor, macroscopic and single-channel currents are intermediate between those of $\alpha 7$ and 5- $\mathrm{HT}_{3 \mathrm{~A}}$ receptors.

Previous studies showed that the structural transition zone separating ligand binding and pore domains is crucial for coupling agonist binding to channel gating (Fig. 1) (Kash et al., 2003; Bouzat et al., 2004; Chakrapani et al., 2004; Grutter et al., 2005; Lee and Sine, 2005; Lummis et al., 2005; Reeves et al., 2005; Xiu et al., 2005; Mercado and Czajkowski, 2006; Castillo et al., 2006; Gee et al., 2007). Furthermore, the functional contribution of this region depends on structural matching of residues projecting from the two domains (Bouzat et al., 2004). Because the coupling region of the $\alpha 7-5 \mathrm{HT}_{3 \mathrm{~A}}$ chimera contains residues from both $\alpha 7$ and $5-\mathrm{HT}_{3 \mathrm{~A}}$ receptors, we hypothesized that the intermediate kinetic profile of the chimera arises from structural mismatching among incongruous residues in the interdomain loops.

To test this hypothesis, we generated two additional chimeras starting from the $\alpha 7-5 \mathrm{HT}_{3 \mathrm{~A}}$ chimera: an all-5 $\mathrm{HT}_{3 \mathrm{~A}}$ chimera in which major loops within the interface dividing extracellular and transmembrane domains contain residues solely from the $5-\mathrm{HT}_{3 \mathrm{~A}}$ receptor and an all- $\alpha 7$ chimera in which these loops contain residues solely from the $\alpha 7$ receptor. Residue substitutions were generated in the following structural regions: the Cys loop, the $\beta 8-\beta 9$ loop, the M2-M3 loop, the $\mathrm{C}$ terminus of $\beta$-strand 10, and the $\mathrm{N}$ terminus of M1 (Fig. 1, Table 1); the amino acid sequence of the $\beta 1-\beta 2$ loop is identical between $\alpha 7$ and $5-\mathrm{HT}_{3 \mathrm{~A}}$ receptors and thus was not modified.

For the all-5 $\mathrm{HT}_{3 \mathrm{~A}}$ chimera, the kinetics of macroscopic and single-channel currents approach those of the $5-\mathrm{HT}_{3 \mathrm{~A}}$ receptor (Fig. 2, Table 2), exhibiting slow desensitization and clusters of many long single-channel openings. The distribution of open times is described by the sum of three exponential components, similar to that of $5-\mathrm{HT}_{3 \mathrm{~A}}$ receptors (Table 2). The distribution of closed times is described by the sum of five exponential components and contains a major brief component of closings within 
intracluster bursts, similar to the $5-\mathrm{HT}_{3 \mathrm{~A}}$ receptor. Unlike the $5-\mathrm{HT}_{3 \mathrm{~A}}$ receptor, however, the all-5 $\mathrm{HT}_{3 \mathrm{~A}}$ chimera exhibited brief $\left(\tau_{\mathrm{o}}=\right.$ $70 \mu \mathrm{s})$ and intermediate $\left(\tau_{\mathrm{o}}=620 \mu \mathrm{s}\right)$ openings in the absence of ACh (supplemental Fig. 2, available at www.jneurosci.org as supplemental material), indicating the equilibrium constant for spontaneous channel gating is greater for the chimera than for either parent receptor.

Analogously for the all- $\alpha 7$ chimera, the kinetics of macroscopic and single-channel currents approach those of the $\alpha 7$ receptor, exhibiting fast desensitization and brief channel openings (Fig. 2). Unlike the all-5 $\mathrm{HT}_{3 \mathrm{~A}}$ chimera, macroscopic currents were small and difficult to detect. Because the total number of $\alpha$-BTX binding sites (data not shown) and the unitary current amplitude (Fig. 2) are similar to those of the template $\alpha 7-5 \mathrm{HT}_{3 \mathrm{~A}}$ chimera, the probability of channel opening may be low for this chimera.

For the all- $\alpha 7$ chimera, the distribution of open times is described by the sum of two exponential components, the longest of which is briefer than that for the $\alpha 7-5 \mathrm{HT}_{3 \mathrm{~A}}$ chimera but longer than that for the native $\alpha 7$ receptor. Closed time histograms are described by the sum of several exponential components, but the distribution was likely altered by the need to modify the recording method. For the all- $\alpha 7$ chimera in the cellattached mode, channel openings were too infrequent to obtain statistically meaningful dwell time distributions, so we recorded currents from outside-out patches to which a step pulse of agonist was applied; after decay of the initial macroscopic current, singlechannel openings could be discerned. However, the long closed intervals between independent openings increased as the recordings progressed, thus altering the closed time distribution. Also, channel activity decayed rapidly and almost disappeared in $<10 \mathrm{~s}$ in the presence of $1 \mathrm{~mm}$ ACh. Therefore, data from several applications of ACh to the same patch were used to obtain dwell time histograms. Nevertheless, within bursts, the open and closed dwell times should not be affected.

We also measured competition of ACh against the initial rate of $\left[{ }^{125} \mathrm{I}\right] \alpha$-BTX binding to intact cells expressing the all-5 $\mathrm{HT}_{3 \mathrm{~A}}$ and all- $\alpha 7$ chimeras. The apparent $K_{d}$ values for ACh of both chimeras were much lower than that of the template $\alpha 7-5 \mathrm{HT}_{3 \mathrm{~A}}$ chimera (Table 2), which is expected because openchannel lifetime is enhanced in the all-5 $\mathrm{HT}_{3 \mathrm{~A}}$ chimera and desensitization is enhanced in the all- $\alpha 7$ chimera.

To compare the kinetic signatures of the all- $5 \mathrm{HT}_{3 \mathrm{~A}}$ and all- $\alpha 7$ chimeras to those of the parent receptors, we computed the mean durations of openings, bursts, and clusters, and the current decay time constant (Fig. 4). For the all-5HT $\mathrm{H}_{3 \mathrm{~A}}$ chimera, the four parameters show a pattern similar to that of the $5-\mathrm{HT}_{3 \mathrm{~A}}$ receptor: the mean duration of long openings is much briefer than both the

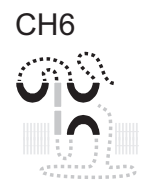

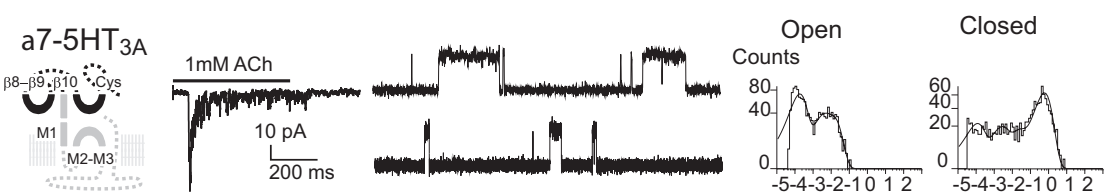
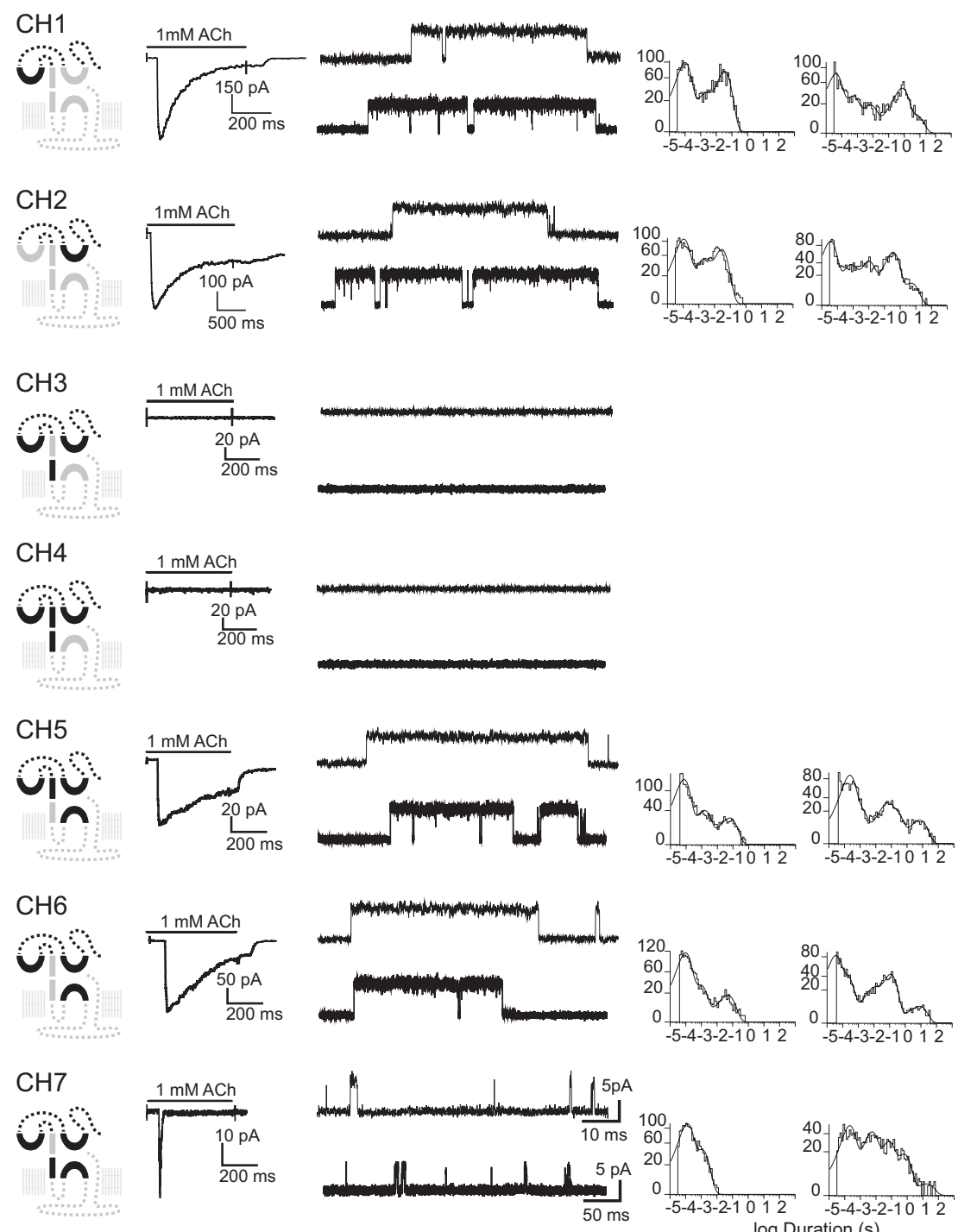

Figure 5. Contributions of different loop regions at the interface to the single-channel dwell times and rate of desensitization. Schematic diagrams of each chimera are shown in the left, as in Figure 2. For most chimeras, macroscopic currents were recorded from outside-out patches and single-channel currents from cell-attached patches. For chimera $\mathrm{CH}_{2}$, macroscopic currents could not be detected from outside-out patches probably attributable to rundown, so unitary currents were recorded in the whole-cell configuration. For chimera $\mathrm{CH}$, single-channel currents could not be detected from cell-attached patches and were recorded in the outside-out patch configuration. Macroscopic currents were elicited by 1 mm ACh. Agonist concentrations for single-channel currents are as in Table 2. For all $\alpha 7-5 \mathrm{HT}_{3 \mathrm{~A}}$ chimeras, the high-conductance forms were used (see Materials and Methods).

mean duration of clusters and the time constant of macroscopic current decay. As observed for the $5-\mathrm{HT}_{3 \mathrm{~A}}$ receptor, mean cluster duration and time constant of current decay were similar. For the all- $\alpha 7$ chimera, openings do not appear in clusters, and the mean open and burst durations are similar, as observed for the parent $\alpha 7$ receptor. However, for the all- $\alpha 7$ chimera, the current decay time constant is approximately twice the mean burst duration, perhaps because the currents were small and the modified recording method altered the closed time distribution and thus assignment of the critical closed time used to construct bursts. 
a

$10 \mu \mathrm{M} \mathrm{ACh}$

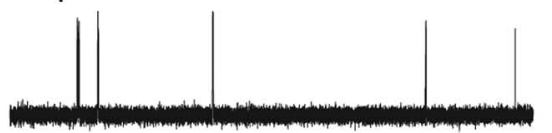

$100 \mu \mathrm{M}$ ACh

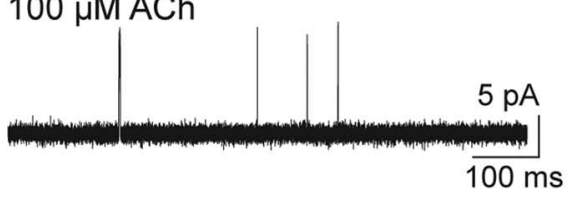

$100 \mathrm{~ms}$

b

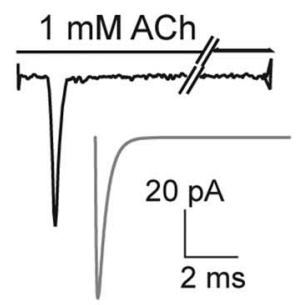

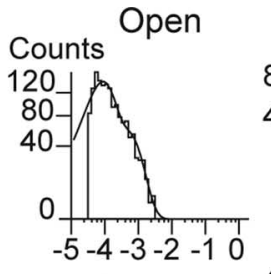

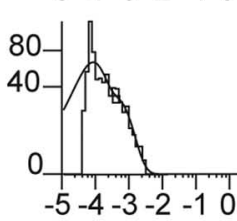

log Duration (s)
Closed

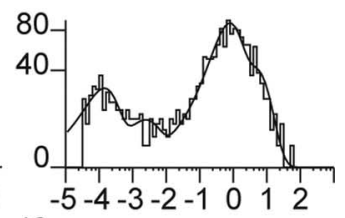

$20-1$

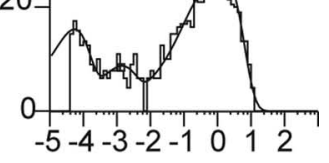

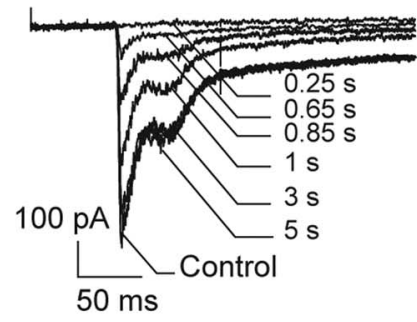

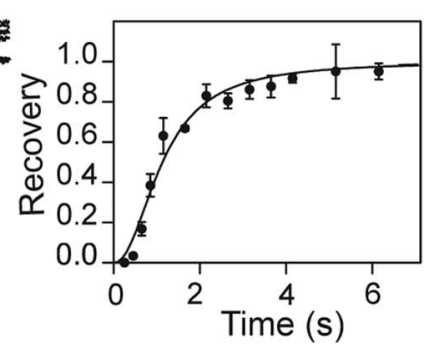

Figure 6. Desensitization governs open-channel lifetime of $\alpha 7$ receptors. $\boldsymbol{a}$, Single-channel currents and dwell time histograms for homomeric $\alpha 7$ receptors recorded in the cell-attached patch configuration in the presence of the indicated $\mathrm{ACh}$ concentrations. The predominant activation episodes are isolated brief openings with amplitude $9.6 \pm 1.7 \mathrm{pA}(-70 \mathrm{mV})$. Openings are upward deflections. Dwell time histograms are fitted by sums of exponentials (smooth curves). $\boldsymbol{b}$, Left, Macroscopic current elicited by a $500 \mathrm{~ms}$ pulse of $1 \mathrm{~mm} \mathrm{ACh}$ applied to an outside-out patch. Rise time, $0.15 \mathrm{~ms}$. Inset, Macroscopic currents were simulated using Scheme 1 and rate constants obtained by analyzing single-channel currents evoked by $100 \mu \mathrm{m} \mathrm{ACh}$ (see Results). The decay time constant obtained from fitting an exponential decay to the simulated current, with $\beta=20,000 \mathrm{~s}^{-1}$, is $0.34 \mathrm{~ms}$. Values of $\beta$ from 5000 to $20,000 \mathrm{~s}^{-1}$ produced negligible differences in the rise time and decay rate. Middle, Time course of recovery from desensitization. After establishing the whole-cell configuration, a pulse of $1 \mathrm{~mm} A \mathrm{ACh}$ was applied to a cell for $150 \mathrm{~ms}$. After removal of ACh, a second pulse of ACh was applied at intervals from 0.25 to $6 \mathrm{~s}$. Note the response to the second ACh pulse recovers completely. Currents evoked by the test pulses decay more slowly and exhibit a complex time course compared with those from outside-out patches, probably attributable to slower and non-uniform perfusion inherent to the whole-cell configuration. Right, Fractional recovery is plotted against time after ACh removal and fitted by a single exponential with time constant of $1.10 \pm 0.08 \mathrm{~s}$.

Quantitative differences in time constants between the chimeras and parent receptors are expected because the template used to generate the chimeras contains $\alpha 7$ sequence in the ligand binding domain and $5-\mathrm{HT}_{3 \mathrm{~A}}$ sequence in the pore and cytoplasmic domains. Nevertheless, substitution of residues from the parent receptors into the extracellular-transmembrane domain interface of the $\alpha 7-5 \mathrm{HT}_{3 \mathrm{~A}}$ chimera reconstitutes the fundamental activation and desensitization properties of the parent homomeric receptors. Thus, residues at the confluence of the ligand binding and pore domains are major determinants of the diverging openchannel lifetimes and rates of desensitization of homomeric $\alpha 7$ and $5-\mathrm{HT}_{3 \mathrm{~A}}$ receptors.

\section{Contributions of loops at the extracellular-transmembrane domain interface to gating kinetics and response termination pathway}

We next sought to determine which loops within the extracellular-transmembrane domain interface contribute to the diverging open-channel lifetimes and rates of desensitization of $5-\mathrm{HT}_{3 \mathrm{~A}}$ and $\alpha 7$ receptors. Starting with the $\alpha 7-5 \mathrm{HT}_{3 \mathrm{~A}}$ chimera, we substituted $5-\mathrm{HT}_{3 \mathrm{~A}}$ for $\alpha 7$ sequences into either the Cys or the $\beta 8-\beta 9$ loops, forming chimeras $\mathrm{CH} 1$ and $\mathrm{CH} 2$, respectively. For both $\mathrm{CH} 1$ and $\mathrm{CH} 2$, macroscopic currents elicited by a step pulse

of a high concentration of ACh rise rapidly and decay slowly, whereas the corresponding single-channel currents appear as clusters of long openings in quick succession (Fig. 5, Table 2). Dwell time histograms for $\mathrm{CH} 1$ and $\mathrm{CH} 2$ are similar, with the longest component of openings similar to the longest component of openings for the all$5 \mathrm{HT}_{3 \mathrm{~A}}$ chimera. Thus, $\mathrm{CH} 1$ and $\mathrm{CH} 2$ exhibit functional signatures approaching that of the all- $5 \mathrm{HT}_{3 \mathrm{~A}}$ chimera, showing that the individual contributions of the Cys and $\beta 8-\beta 9$ loops are approximately equal but not additive.

Chimeras $\mathrm{CH} 1$ and $\mathrm{CH} 2$ nevertheless differ functionally from the all-5 $\mathrm{HT}_{3 \mathrm{~A}}$ chimera; both chimeras show lower apparent affinity for ACh, higher concentrations of $\mathrm{ACh}$ are required to elicit single-channel currents, and spontaneous single-channel openings are not observed (Table 2). Thus, $5-\mathrm{HT}_{3 \mathrm{~A}}$ sequences are required in both the Cys and $\beta 8-\beta 9$ loops to achieve the complete functional signature of the all- $5 \mathrm{HT}_{3 \mathrm{~A}}$ chimera.

To assess the contribution of the $\mathrm{N}$ terminus of M1, we again started with the $\alpha 7-5 \mathrm{HT}_{3 \mathrm{~A}}$ chimera and substituted $\alpha 7$ for $5-\mathrm{HT}_{3 \mathrm{~A}}$ sequences in this region. The resulting chimera, $\mathrm{CH} 3$, expressed in robust quantities on the cell surface (84 $\pm 7 \%$ relative to the $\alpha 7-5 \mathrm{HT}_{3 \mathrm{~A}}$ chimera), but ACh did not elicit single-channel or macroscopic currents (20 whole-cell recordings from cells confirmed to be transfected) (Fig. 5). Measurements of competition of ACh against the initial rate of $\left[{ }^{125} \mathrm{I}\right] \alpha$-BTX binding revealed an apparent $K_{d}$ similar to that of the starting $\alpha 7$ $5 \mathrm{HT}_{3 \mathrm{~A}}$ chimera (Table 2). A second chimera, $\mathrm{CH} 4$, containing $\alpha 7$ substitutions in both $\mathrm{M} 1$ and the contiguous $\beta$-strand 10, expressed on the cell surface ( $47 \pm 18 \%$ relative to the $\alpha 7-5 \mathrm{HT}_{3 \mathrm{~A}}$ chimera) and bound ACh with an apparent $K_{d}$ similar to that of the $\alpha 7-5 \mathrm{HT}_{3 \mathrm{~A}}$ chimera (Table 2), but again ACh did not elicit single-channel or macroscopic currents (30 whole-cell recordings from cells confirmed to be transfected). In both $\mathrm{CH} 3$ and $\mathrm{CH} 4$, the M2-M3 loop contains $5-\mathrm{HT}_{3 \mathrm{~A}}$ sequences, whereas the $\mathrm{N}$ terminus of $\mathrm{M} 1$ contains $\alpha 7$ sequences, suggesting that a structural mismatch between these two regions can functionally decouple the ligand binding and pore domains.

To further examine functional consequences of mismatches between the $\mathrm{N}$ terminus of M1 and the M2-M3 loop, we substituted $5-\mathrm{HT}_{3 \mathrm{~A}}$ sequences into $\mathrm{M} 1$ and $\alpha 7$ sequences into M2-M3, thus reversing the mismatch in the functionally silent chimeras $\mathrm{CH} 3$ and $\mathrm{CH} 4$. The resulting chimeras, $\mathrm{CH} 5$ and $\mathrm{CH} 6$, exhibit robust macroscopic and single-channel currents in response to ACh and display functional signatures approaching that of the all- $5 \mathrm{HT}_{3 \mathrm{~A}}$ chimera; after a pulse of ACh to outside-out patches, the currents decay slowly from their peaks, and, in cell attached patches, single-channel currents appear as clusters of many long openings flanked by brief closings (Fig. 5, Table 2). For chimeras $\mathrm{CH} 5$ and $\mathrm{CH} 6$, dwell time histograms and apparent affinity for $\mathrm{ACh}$ approach those for the all-5 $\mathrm{HT}_{3 \mathrm{~A}}$ chimera, and single- 
channel currents in the absence of ACh were observed, similar to the all- $5 \mathrm{HT}_{3 \mathrm{~A}}$ chimera. Thus, the results from chimeras $\mathrm{CH} 3$ through $\mathrm{CH} 6$ reveal that the combination of sequences of $\mathrm{M} 1$ and the M2-M3 loop can affect coupling of agonist binding to channel gating and that the presence of $5-\mathrm{HT}_{3 \mathrm{~A}}$ sequence in $\mathrm{M} 1$ confers long open-channel lifetime and slow rate of desensitization, although the M2-M3 loop contains $\alpha 7$ sequences.

Remarkably, substitution of $\alpha 7$ sequence into M1 of $\mathrm{CH} 6$ to form $\mathrm{CH} 7$, an exchange of only five residues (Table 1), converts the slow kinetics characteristic of $5-\mathrm{HT}_{3 \mathrm{~A}}$ receptors to fast kinetics characteristic of $\alpha 7$ receptors and the all- $\alpha 7$ chimera (Fig. 5, Table 2). Thus, four discontinuous regions of the primary sequence, the Cys loop, $\beta 8-\beta 9$ loop, M2-M3 loop, and N terminus of M1, converge at the interface dividing extracellular, and transmembrane domains contribute to coupling between the binding site and the pore, open-channel lifetime, and the rate of desensitization.

\section{Open-channel lifetime of $\alpha 7$ receptors is governed by desensitization}

In the presence of a high concentration of $\mathrm{ACh}, \alpha 7$ receptors activate predominantly as single brief openings flanked by long closed periods (Fig. 2). This simple temporal pattern of current pulses has several possible explanations: the rate constant for channel opening could be slow, ACh could associate slowly, dissociate rapidly, or both, or desensitization could be unusually rapid. In cell-free outside-out patches, macroscopic currents through $\alpha 7$ receptors reach a peak within the solution exchange time of $<1 \mathrm{~ms}$ (Fig. $6 b$ ), eliminating a slow rate of channel opening as the explanation. To test for a contribution of ACh association and dissociation, we recorded single-channel currents in the presence of low and high ACh concentrations, reasoning that, over the range of ACh concentrations that elicit single-channel currents, contributions of $\mathrm{ACh}$ association and dissociation should affect the temporal pattern of the unitary current pulses. However, the dwell time distributions do not change from 10 to $100 \mu \mathrm{M}$ ACh, showing no evidence for contributions of ACh association or dissociation to the single-channel kinetics (Fig. $6 a)$. Finally, mean channel open time, mean burst duration, and time constant for desensitization are all similar (Fig. 4), indicating that rapid desensitization is the most likely explanation for the novel single-channel kinetics of $\alpha 7$ receptors.

To gain quantitative insight into the open-channel lifetime of $\alpha 7$ receptors, we analyzed the kinetics of bursts according to the following:

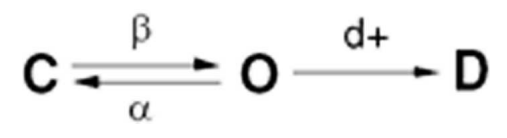

(Scheme 1)

where $\mathrm{C}$ is the fully liganded closed state, $\mathrm{O}$ is the open state, and $\mathrm{D}$ is the desensitized state (Auerbach and Akk, 1998; Mike et al., 2000). States C and D are both nonconducting but are kinetically distinguishable. Fully liganded closed receptors open with rate constant $\beta$, whereas open receptors either close with rate constant $\alpha$ or desensitize with rate constant $\mathrm{d}+$. Because the concentration of agonist is saturating, we can assume all transitions away from $\mathrm{C}$ regenerate $\mathrm{O}$. Furthermore, because $\mathrm{D}$ is a long-lived state, dwells in C are brief compared with dwells in D, and transitions from $\mathrm{D}$ to $\mathrm{O}$ can be neglected. Thus, in the presence of a saturating concentration of $\mathrm{ACh}$, Scheme 1 predicts that the number of closings per burst is $\alpha / \mathrm{d}+$, the mean duration of openings within bursts is $(\alpha+\mathrm{d}+)^{-1}$, and the mean burst duration is approximately $(1+\alpha / \mathrm{d}+) /(\alpha+\mathrm{d}+)$.

Thus, for $\alpha 7$ receptors, we quantified the number of closings per burst $(0.30 \pm 0.19)$ and the corrected mean open time of openings within bursts $(0.26 \pm 0.12 \mathrm{~ms})$ and obtained estimates of $\alpha$ and $d+$ of $690 \pm 300$ and $3320 \pm 1300 \mathrm{~s}^{-1}$, respectively. The analysis reveals that the rate constant for desensitization, $d+$, is much greater than the rate constant for channel closing, $\alpha$. Analysis according to Scheme 1 assumes a single kinetic class of openings within bursts, but our open time histograms show a second component of brief openings. However, bursts contain predominantly long-duration openings because the long-duration component in the open-duration histogram shifts to longer time during formation of bursts, whereas the mean duration of the brief component is unchanged (Fig. 3). Thus, for $\alpha 7$ receptors, the estimated values of $\alpha$ and $\mathrm{d}+$ in Scheme 1 account for the mean duration of bursts of openings. Furthermore, using the fitted values of $\alpha$ and $\mathrm{d}+$ and assuming a rapid rate of channel opening, the simulated macroscopic current mimics the experimental response (Fig. 6b).

Control of open-channel lifetime through desensitization has potential consequences for inter-response latency at the synapse in which the pulse of neurotransmitter is transient. If $\alpha 7$ receptors recover slowly from desensitization, the minimum latency between successive responses would be long. Thus, we measured the time course of recovery from desensitization using a twinpulse procedure: a pulse of agonist was applied, the agonist was removed, and, after increasing recovery times, a second pulse of agonist was applied. To obtain sufficiently large currents, we performed recovery experiments in the whole-cell recording mode. After a $150 \mathrm{~ms}$ desensitizing pulse of ACh, current elicited by the second pulse recovers with a time constant of $\sim 1 \mathrm{~s}$. We found that currents elicited by the test pulses decayed more slowly in the whole-cell mode than in the outside-out patch mode, likely attributable to differences in the speed and uniformity of exposure of the receptors to the agonist, which may account for variability in reported rates of desensitization for $\alpha 7$ receptors (Gopalakrishnan et al., 1995; Zhang et al., 1996; Liu and Berg, 1999; Mike et al., 2000). Nevertheless, in whole-cell mode, the current reaches a peak in $<10 \mathrm{~ms}$ and decays by $>80 \%$ of the original peak during the $150 \mathrm{~ms}$ pulse of ACh. Thus, after rapid desensitization of $\alpha 7$ receptors, a latency of several seconds is required to generate another response of full amplitude.

\section{Discussion}

We demonstrate diverging open-channel lifetimes and desensitization rates by homomeric $\alpha 7$ and $5-\mathrm{HT}_{3 \mathrm{~A}}$ receptors and show that these differences arise primarily from differences in residues at the confluence of the extracellular and transmembrane domains. Within this region, separate segments of the linear sequence converge to form an intra-subunit network that governs both functional properties in parallel. When the interface contains residues from the $\alpha 7$ receptor, the open-channel lifetime is brief because of unusually rapid formation of a long-lived desensitized state. In contrast, when the interface contains residues from the $5-\mathrm{HT}_{3 \mathrm{~A}}$ receptor, the open-channel lifetime is prolonged, many openings occur in quick succession, and the resulting clusters of openings are long because of slow formation of a desensitized state. The different structural loops at the interface contribute to the functional signature of the receptor in a nonadditive manner, and further, certain combinations of the loops can functionally decouple the binding domain from the pore domain. Thus, in addition to its established role in coupling agonist 
binding to channel gating (Kash et al., 2003; Bouzat et al., 2004; Chakrapani et al., 2004; Lee and Sine, 2005; Lummis et al., 2005; Reeves et al., 2005; Xiu et al., 2005; Castillo et al., 2006; Mercado and Czajkowski, 2006), the interface dividing extracellular and transmembrane domains can be structurally modified to generate a wide range of open-channel lifetimes and rates of desensitization. Although desensitization is likely an important contributor to synaptic efficacy in normal and pathological conditions, structural bases for desensitization have been particularly elusive (Giniatullin et al., 2005). Our work shows that the interface dividing extracellular and transmembrane domains of homomeric Cys-loop receptors affects open-channel lifetime and rate of desensitization in parallel and that these processes contribute to termination of the synaptic response.

Coupling agonist binding to channel gating likely requires coordinated structural changes among multiple loops at the interface, implying a working assembly in which the loops are structurally compatible. Evidence for structural compatibility of the loops emerged from studies of chimeric receptors in which the extracellular domain was built from ACh binding protein and the transmembrane domain from the $5-\mathrm{HT}_{3 \mathrm{~A}}$ receptor (Bouzat et al., 2004). The requirement for structural compatibility further suggests that the functional contribution of each loop depends on the structures of juxtaposed loops, which was demonstrated by inter-residue energetic coupling in this region of the muscle AChR (Lee and Sine, 2005). Here we show that the functional contributions of the $\mathrm{N}$ terminus of $\mathrm{M} 1$, the $\beta 8-\beta 9$ loop, and the Cys loop depend on the structures of the other loops. Additional structures at the periphery of the interfacial region, including the ends of the M3 and M $4 \alpha$-helices and the C terminus, may potentially contribute to this functional network (Xiu et al., 2005). Whether these additional structures contribute to open-channel lifetime and desensitization represents an important question for future studies.

We find that the $\beta 8-\beta 9$ and Cys loops contribute to openchannel lifetime and rate of desensitization in a nonadditive manner; substitution of $5-\mathrm{HT}_{3 \mathrm{~A}}$ sequence into either or both loops prolongs the open-channel lifetime and slows desensitization. Because the two loops do not make physical contact, the structural basis for the nonadditive contributions may result from interaction with a structure common to both loops. A good candidate is $\beta$-strand 10, which is lodged between the loops and contains the invariant $\alpha$ Arg 209 key to the functional linkage between extracellular and transmembrane domains (Lee and Sine, 2005). Thus, the $\beta 8-\beta 9$ and Cys loops may modulate $\beta$-strand 10 , which in turn may be decisive in determining openchannel lifetime and rate of desensitization.

Our findings also reveal novel contributions of the N-terminal region of M1. If M1 contains $\alpha 7$ sequence and the M2-M3 loop contains $5-\mathrm{HT}_{3 \mathrm{~A}}$ sequence, the response to agonist is blocked, showing that $\mathrm{M} 1$ is selectively permissive for an agonist-mediated response. Conversely, if $\mathrm{M} 1$ contains $5-\mathrm{HT}_{3 \mathrm{~A}}$ sequence, a response can be elicited whether the M2-M3 loop contains either $\alpha 7$ or $5-\mathrm{HT}_{3 \mathrm{~A}}$ sequence. Thus, the ability of agonist to elicit a response depends on the combination of the sequences of M1 and the M2-M3 loop. M1 is proximal to the N terminus of the M2-M3 loop (Unwin, 2005), suggesting that the two regions may interact directly. Inspection of the Torpedo AChR structural model reveals subsegments of M1 and the M2-M3 loop in close proximity. Within $\mathrm{M} 1$ of $\alpha 7$, this contact region contains the sequence Thr-Leu-Tyr (Table 1), which is selectively permissive for generating a response to agonist, whereas in $\mathrm{M} 1$ of $5-\mathrm{HT}_{3 \mathrm{~A}}$, the contact region contains Pro-Leu-Phe, which is permissive.
Within the M2-M3 loop of $\alpha 7$, the contact region contains the sequence Ser-Asp-Ser, which is the only one compatible with the selectively permissive sequence from M1 of $\alpha 7$, although within the M2-M3 loop of 5- $\mathrm{HT}_{3 \mathrm{~A}}$, the contact region contains Ala-IleuGly, which is compatible with either of the M1 sequences. Residues within these regions constitute logical starting points for investigating possible inter-residue interactions that affect the ability of the binding domain to couple to the pore. Alternatively, the different M1 segments may alter the contiguous $\beta$-strand 10 and its link to the $\beta 1-\beta 2$ loop, as suggested above, or possibly they may affect the adjoining M3 domain of the neighboring subunit.

The $\mathrm{N}$ terminus of M1 is also decisive in conferring openchannel lifetime and rate of desensitization; if M1 contains the sequence from the $5-\mathrm{HT}_{3 \mathrm{~A}}$ receptor, channel openings are long and desensitization is slow, regardless of whether the M2-M3 sequence is from $\alpha 7$ or $5-\mathrm{HT}_{3 \mathrm{~A}}$ receptors. However, the decisive contribution of $5-\mathrm{HT}_{3 \mathrm{~A}}$ sequences from $\mathrm{M} 1$ is not absolute because it can be modulated by neighboring loops; when $\alpha 7$ sequence is present in the Cys loop and $\beta 8-\beta 9$ loop, as in the starting $\alpha 7-5 \mathrm{HT}_{3 \mathrm{~A}}$ chimera, open-channel lifetime and desensitization rate are intermediate, although $5-\mathrm{HT}_{3 \mathrm{~A}}$ sequence is present in M1. Additional studies are required to determine whether the decisive contribution of the M1 sequence from the $5-\mathrm{HT}_{3 \mathrm{~A}}$ receptor results from direct interaction with the $\mathrm{M} 2-\mathrm{M} 3$ loop or a propagated interaction to the contiguous $\beta$-strand 10 or to the neighboring subunit.

We find that structural changes at the interfacial region also produce changes in the apparent $K_{d}$ for ACh binding. Because the binding measurements are made at steady state, channel gating, desensitization, and ACh affinity for the different functional states all contribute to the apparent $K_{d}$. Thus, binding measurements alone give little insight into the origin of a functional change, but they can confirm that a functional change occurred. For example, the all-5 $\mathrm{HT}_{3 \mathrm{~A}}$ chimera shows significantly enhanced gating, as observed by the high spontaneous activity and the long-duration openings, in line with the large decrease in the apparent $K_{d}$ relative to the starting $\alpha 7-5 \mathrm{HT}_{3 \mathrm{~A}}$ chimera. Conversely, the all- $\alpha 7$ chimera desensitizes so strongly that singlechannel currents could only be recorded in the outside-out patch configuration, which is confirmed by the decrease in $K_{d}$ relative to that of the starting $\alpha 7-5 \mathrm{HT}_{3 \mathrm{~A}}$ chimera. Finally, binding measurements showed that the $\mathrm{CH} 3$ and $\mathrm{CH} 4$ chimeras bound $\mathrm{ACh}$ with an apparent $K_{d}$ similar to that of the $\alpha 7-5 \mathrm{HT}_{3 \mathrm{~A}}$ chimera, although ACh failed to evoked single-channel or macroscopic currents. Thus, binding and functional measurements together indicate that, in the context of 5- $\mathrm{HT}_{3 \mathrm{~A}}$ sequences in the $\mathrm{M} 2-\mathrm{M} 3$ loop, $\alpha 7$ sequences in M1 decouple binding from gating.

The kinetics of $\alpha 7$ receptors contrast with those of nicotinic receptors at the motor synapse, which in the presence of low concentrations of ACh, exhibit bursts of several openings separated by brief closings. This bursting pattern arises because the rate constant for channel opening is greater than the rate constant for ACh dissociation, enabling reopening of the di-liganded receptor channel (Colquhoun and Sakmann, 1981). Bursts elicited by low ACh concentrations are the single-channel counterpart of endplate currents (EPCs) evoked by nerve-released ACh (Colquhoun and Sakmann, 1985); mean burst duration and the time constant of EPC decay have been shown to be equal (Sine et al., 1995b). Conversely, single-channel currents elicited by high concentrations of ACh occur in clusters of tens to hundreds of channel openings in rapid succession. Each cluster begins when a receptor recovers from the long-lived desensitized state and, in 
the continued presence of agonist, undergoes repeated cycles of channel closing, agonist dissociation, agonist rebinding, and channel opening until the receptor reenters the desensitized state. Thus, because the rate of desensitization is slow compared with the rate of channel closing, single-channel currents elicited by high ACh concentrations appear in prolonged clusters. For $\alpha 7$ receptors, in contrast, the temporal pattern of single-channel currents does not change from low to high ACh concentrations, and the elementary activation episodes consist primarily of a single opening flanked by long closings. This simple pattern arises because the rate of desensitization is rapid compared with the rate of channel closing, so that repeated cycles of channel closing and reopening are rare. Our estimates of the rates of channel closing and desensitization indicate that approximately three of four channel openings terminate by desensitization rather than by channel closing.

In an alternative arrangement of states from those in Scheme 1 , the desensitized closed state D could be connected to the fully liganded closed state $\mathrm{C}$ rather than the open state $\mathrm{O}$. Given this alternative, the observed number of brief closings per burst of 0.3 should equal $\beta / d+$, where $\beta$ is the channel opening rate of the fully liganded receptor. Given the measured rate of desensitization for $\alpha 7$ receptors of $2500 \mathrm{~s}^{-1}$, the channel opening rate is predicted to be $750 \mathrm{~s}^{-1}$. However, a lower limit for $\beta$ is given by the rise time of the current elicited by a saturating concentration of ACh. The measured rise time of $0.15 \mathrm{~ms}$ places a lower limit on $\beta$ of $6667 \mathrm{~s}^{-1}$, which is much greater than the value of $750 \mathrm{~s}^{-1}$ predicted from the kinetics of single-channel currents. Expressed another way, the alternative scheme gives a time constant for desensitization of $0.3 \mathrm{~ms}$ if $\beta=20,000 \mathrm{~s}^{-1}, \alpha=3800 \mathrm{~s}^{-1}$, and $\mathrm{d}+$ $=100,000 \mathrm{~s}^{-1}$. However, this set of rate constants predicts a mean duration of brief closings of $8 \mu \mathrm{s}$, contrary to the observed $117 \mu$ s (Fig. 3). Thus, Scheme 1, in which the desensitized state D is connected to the open state $\mathrm{O}$, best describes the data.

Although 5- $\mathrm{HT}_{3 \mathrm{~A}}$ and $\alpha 7$ receptors diverge functionally, they also show functional parallels. The diverging properties include open states with differing stability, closed states differing in number and probability of occurrence, and differing rates of desensitization. Furthermore, Scheme 1, which describes the activation kinetics of $\alpha 7$ receptors in the presence of a saturating concentration of $\mathrm{ACh}$, cannot describe the activation kinetics of 5- $\mathrm{HT}_{3 \mathrm{~A}}$ receptors; additional open and closed states are required (Solt et al., 2007). However, the two types of receptors show the functional parallel that the distributions of open, closed, and burst or cluster durations do not depend on agonist concentration. This concentration-independence of single-channel kinetics agrees with the recent findings by Solt et al. (2007), who showed that, for $5-\mathrm{HT}_{3 \mathrm{~A}}$ receptors, the rate of desensitization elicited by a high concentration of 5-HT was similar to the rate of deactivation after a brief pulse of 5-HT. Thus, although the response time courses of $\alpha 7$ and 5- $\mathrm{HT}_{3 \mathrm{~A}}$ receptors differ markedly, for both receptors desensitization governs the lifetimes of the elementary activation episodes.

The kinetics of $\alpha 7$-mediated responses described here qualitatively mirrors the kinetics of agonist-mediated responses recorded from hippocampal neurons rich in $\alpha 7$ receptors (Dani et al., 2000; Mike et al., 2000). Similar to $\alpha 7$, desensitization of AMPA receptors is rapid enough to contribute to open-channel lifetime and the decay of the postsynaptic response, and recovery from desensitization is slow enough to affect inter-response latency (Jones and Westbrook, 1996). $\alpha 7$ receptors thus constitute a remarkable extreme of rapid desensitization and slow channel closing; desensitization rate is so rapid that it is the major deter- minant of the open-channel lifetime $\left(\tau_{\mathrm{o}}=0.4 \mathrm{~ms}\right)$, and recovery from desensitization is so slow $\left(\tau_{\text {recovery }}=1 \mathrm{~s}\right)$ that the interresponse latency is expected to be prolonged. Thus, although $\alpha 7$ receptors act as high-fidelity sensors of ACh concentration, they harbor a built-in filtering mechanism against excessive stimulation.

The interface dividing extracellular and transmembrane domains contains a significant proportion of nonconserved residues, suggesting that different subtypes of Cys-loop receptors use different residue combinations to tailor postsynaptic responses according to physiological needs. Contributions of the $\beta 1-\beta 2$, Cys, and $\beta 8-\beta 9$ loops have been documented, but the contribution of the $\mathrm{N}$ terminus of $\mathrm{M} 1$ and its dependence on the structure of the M2-M3 loop described here are novel. Thus, the four structural regions at the interface dividing extracellular and transmembrane domains form a structural network that determines the lifetime of the activated receptor and thus the strength and inter-response latency of the postsynaptic response.

\section{References}

Auerbach A, Akk G (1998) Desensitization of mouse nicotinic acetylcholine receptor channels. A two-gate mechanism. J Gen Physiol 112:181-197.

Bouzat C, Bren N, Sine SM (1994) Structural basis of the different gating kinetics of fetal and adult acetylcholine receptors. Neuron 13:1395-1402.

Bouzat C, Barrantes F, Sine SM (2000) Nicotinic receptor fourth transmembrane domain: hydrogen bonding by conserved threonine contributes to channel gating kinetics. J Gen Physiol 115:663-672.

Bouzat C, Gumilar F, del Carmen Esandi M, Sine SM (2002) Subunitselective contribution to channel gating of the M4 domain of the nicotinic receptor. Biophys J 82:1920-1929.

Bouzat C, Gumilar F, Spitzmaul G, Wang HL, Rayes D, Hansen SB, Taylor P, Sine SM (2004) Coupling of agonist binding to channel gating in an ACh-binding protein linked to an ion channel. Nature 430:896-900.

Castillo M, Mulet J, Bernal JA, Criado M, Sala F, Sala S (2006) Improved gating of a chimeric alpha7-5HT3A receptor upon mutations at the M2-M3 extracellular loop. FEBS Lett 580:256-260.

Chakrapani S, Bailey TD, Auerbach A (2004) Gating dynamics of the acetylcholine receptor extracellular domain. J Gen Physiol 123:341-356.

Colquhoun D, Sakmann B (1981) Fluctuations in the microsecond time range of the current through single acetylcholine receptor ion channels. Nature 294:464-466.

Colquhoun D, Sakmann B (1985) Fast events in single-channel currents activated by acetylcholine and its analogues at the frog muscle end-plate. J Physiol 369:501-557.

Dani JA, Radcliffe KA, Pidoplichko VI (2000) Variations in desensitization of nicotinic acetylcholine receptors from hippocampus and midbrain dopamine areas. Eur J Pharmacol 393:31-38.

Dilger JP, Liu Y (1992) Desensitization of acetylcholine receptors in BC3H-1 cells. Pflugers Arch 420:479-485.

Gee VJ, Kracun S, Cooper ST, Gibb AJ, Millar NS (2007) Identification of domains influencing assembly and ion channel properties in alpha 7 nicotinic receptor and 5-HT3 receptor subunit chimaeras. Br J Pharmacol 152:501-512.

Giniatullin R, Nistri A, Yakel JL (2005) Desensitization of nicotinic ACh receptors: shaping cholinergic signaling. Trends Neurosci 28:371-378.

Gopalakrishnan M, Buisson B, Touma E, Giordano T, Campbell JE, Hu IC, Donnelly-Roberts D, Arneric SP, Bertrand D, Sullivan JP (1995) Stable expression and pharmacological properties of the human alpha 7 nicotinic acetylcholine receptor. Eur J Pharmacol 290:237-246.

Grutter T, de Carvalho LP, Dufresne V, Taly A, Edelstein SJ, Changeux JP (2005) Molecular tuning of fast gating in pentameric ligand-gated ion channels. Proc Natl Acad Sci U S A 50:18207-18212.

Gumilar F, Bouzat C (2008) Tricyclic antidepressants inhibit homomeric Cys-loop receptors by acting at different conformational states. Eur J Pharmacol 584:30-39.

Hamill OP, Marty A, Neher E, Sakmann B, Sigworth FJ (1981) Improved patch-clamp techniques for high-resolution current recording from cells and cell-free membrane patches. Pflugers Arch 391:85-100.

Humphrey W, Dalke A, Schulten K (1996) VMD: visual molecular dynamics. J Mol Graph 14:33-38. 
Jha A, Cadugan DJ, Purohit P, Auerbach A (2007) Acetylcholine receptor gating at extracellular transmembrane domain interface: the cys-loop and M2-M3 linker. J Gen Physiol 130:547-558.

Jones MV, Westbrook GL (1996) The impact of receptor desensitization on fast synaptic transmission. Trends Neurosci 19:96-101.

Kash TL, Jenkins A, Kelley JC, Trudell JR, Harrison NL (2003) Coupling of agonist binding to channel gating in the $\operatorname{GABA}(\mathrm{A})$ receptor. Nature 421:272-275.

Katz B, Thesleff S (1957) A quantitative description of end-plate currents. J Physiol 138:63-80.

Kelley SP, Dunlop JI, Kirkness EF, Lambert JJ, Peters JA (2003) A cytoplasmic region determines single-channel conductance in 5-HT3 receptors. Nature 424:321-324.

Lee WY, Sine SM (2005) Principal pathway coupling agonist binding to channel gating in nicotinic receptors. Nature 438:243-247.

Lester HA, Dibas MI, Dahan DS, Leite JF, Dougherty DA (2004) Cys-loop receptors: new twists and turns. Trends Neurosci 27:329-336.

Liu QS, Berg DK (1999) Extracellular calcium regulates responses of both alpha3- and alpha7-containing nicotinic receptors on chick ciliary ganglion neurons. J Neurophysiol 82:1124-1132.

Liu Y, Dilger JP (1991) Opening rate of acetylcholine receptor channels. Biophys J 60:424-432.

Lummis SC, Beene DL, Lee LW, Lester HA, Broadhurst RW, Dougherty DA (2005) Cis-trans isomerization at a proline opens the pore of a neurotransmitter-gated ion channel. Nature 438:248-252.

Magleby KL, Stevens CF (1972) A quantitative description of end-plate currents. J Physiol 223:173-197.

Mercado J, Czajkowski C (2006) Charged residues in the $\alpha 1$ and $\beta 2$ pre-M1 regions involved in $\mathrm{GABA}_{\mathrm{A}}$ receptor activation. J Neurosci 26:2031-2040.

Mike A, Castro NG, Albuquerque EX (2000) Choline and acetylcholine have similar kinetic properties of activation and desensitization on the $\alpha 7$ nicotinic receptors in rat hippocampal neurons. Brain Res 882:155-168.

Mott DD, Erreger K, Banke TG, Traynelis SF (2001) Open probability of homomeric murine $5-\mathrm{HT}_{3 \mathrm{~A}}$ serotonin receptors depends on subunit occupancy. J Physiol 535:427-443.

Mukhtasimova N, Sine SM (2007) An intersubunit trigger of channel gating in the muscle nicotinic receptor. J Neurosci 27:4110-4119.

Mukhtasimova N, Free C, Sine SM (2005) Initial coupling of binding to gating mediated by conserved residues in muscle nicotinic receptor. J Gen Physiol 126:23-39.

Quiram PA, Sine SM (1998) Structural elements in alpha-conotoxin ImI essential for binding to neuronal alpha7 receptors. J Biol Chem 273:11007-11011.

Rayes D, Spitzmaul G, Sine SM, Bouzat C (2005) Single channel kinetic analysis of chimeric $\alpha 7-5 \mathrm{HT}_{3 \mathrm{~A}}$ receptors. Mol Pharmacol 68:1475-1483.

Reeves DC, Jansen M, Bali M, Lemster T, Akabas MH (2005) A role for the $\beta 1-\beta 2$ loop in the gating of 5- $\mathrm{HT}_{3}$ receptors. J Neurosci 25:9358-9366.

Sigworth FJ, Sine SM (1987) Data transformations for improved display and fitting of single-channel dwell time histograms. Biophys J 52:1047-1054.

Sine S, Taylor P (1979) Functional consequences of agonist-mediated state transitions in the cholinergic receptor. J Biol Chem 254:3315-3325.

Sine SM, Engel AG (2006) Recent advances in Cys-loop receptor structure and function. Nature 440:448-455.

Sine SM, Kreienkamp HJ, Bren N, Maeda R, Taylor P (1995a) Molecular dissection of subunit interfaces in the acetylcholine receptor: identification of determinants of alpha-conotoxin M1 selectivity. Neuron 15:205-211.

Sine SM, Ohno K, Bouzat C, Auerbach A, Milone M, Pruitt JN, Engel AG (1995b) Mutation of acetylcholine receptor a subunit causes a slow channel myasthenic syndrome by enhancing agonist binding affinity. Neuron 15:229-239.

Solt K, Ruesch D, Forman SA, Davies PA, Raines DE (2007) Differential effects of serotonin and dopamine on human $5-\mathrm{HT}_{3 \mathrm{~A}}$ receptor kinetics: interpretation within an allosteric kinetic model. J Neurosci 27:13151-13160.

Spitzmaul G, Dilger JP, Bouzat C (2001) The noncompetitive inhibitor quinacrine modifies the desensitization kinetics of muscle acetylcholine receptors. Mol Pharmacol 60:235-243.

Unwin N (2005) Refined structure of the nicotinic acetylcholine receptor at 4 Å resolution. J Mol Biol 346:967-989.

Williams ME, Burton B, Urrutia A, Shcherbatko A, Chavez-Noriega LE, Cohen CJ, Aiyar J (2005) Ric-3 promotes functional expression of the nicotinic acetylcholine receptor alpha7 subunit in mammalian cells. J Biol Chem 280:1257-1263.

Xiu X, Hanek AP, Wang J, Lester HA, Dougherty DA (2005) A unified view of the role of electrostatic interactions in modulating the gating of Cys loop receptors. J Biol Chem 280:41655-41666.

Zhang ZW, Coggan JS, Berg DK (1996) Synaptic currents generated by neuronal acetylcholine receptors sensitive to alpha-bungarotoxin. Neuron 17:1231-1240. 